\title{
Aerosol nucleation over oceans and the role of galactic cosmic rays
}

\author{
J. Kazil ${ }^{1,2}$, E. R. Lovejoy ${ }^{2}$, M. C. Barth ${ }^{3}$, and K. O'Brien ${ }^{4}$ \\ ${ }^{1}$ Cooperative Institute for Research in Environmental Sciences, University of Colorado, Boulder, CO,USA \\ ${ }^{2}$ Atmospheric Chemical Processes Group, Atmospheric Chemistry Division, NOAA ESRL, Boulder, CO, USA \\ ${ }^{3} \mathrm{MMM} / \mathrm{ACD}$, National Center for Atmospheric Research, Boulder, CO, USA \\ ${ }^{4}$ Department of Physics and Astronomy, Northern Arizona University, Flagstaff, AZ, USA
}

Received: 21 April 2006 - Published in Atmos. Chem. Phys. Discuss.: 28 June 2006

Revised: 12 October 2006 - Accepted: 26 October 2006 - Published: 30 October 2006

\begin{abstract}
We investigate formation of sulfate aerosol in the marine troposphere from neutral and charged nucleation of $\mathrm{H}_{2} \mathrm{SO}_{4}$ and $\mathrm{H}_{2} \mathrm{O}$. A box model of neutral and charged aerosol processes is run on a grid covering the oceans. Input data are taken from a model of galactic cosmic rays in the atmosphere, and from global chemistry and transport models. We find a weak aerosol production over the tropical oceans in the lower and middle troposphere, and a stronger production at higher latitudes, most notably downwind of industrial regions. The strongest aerosol production however occurs in the upper troposphere over areas with frequent convective activity, in particular in the tropics. This finding supports the proposition by which non-sea salt marine boundary layer aerosol in tropical regions does not form in situ, but nucleates in the upper troposphere from convectively lifted and cloud processed boundary layer air rich in aerosol precursor gases, from where it descends in subsiding air masses compensating convection. Convection of boundary layer air also appears to drive the formation of condensation nuclei in the tropical upper troposphere which maintains the stratospheric aerosol layer in the absence of volcanic activity. Neutral nucleation contributes only marginally to aerosol production in our simulations. This highlights the importance of other mechanisms, including charged binary and ternary, and neutral ternary nucleation for aerosol formation. Our analysis indicates that the variation of ionization by galactic cosmic rays over the decadal solar cycle does not entail a response in aerosol production and cloud cover via the second indirect aerosol effect that would explain observed variations in global cloud cover. We estimate that the variation in radiative forcing resulting from a response of clouds to the change in galactic cosmic ray ionization and subsequent aerosol production over the decadal solar cycle is smaller than the concurrent variation of total solar irradiance.
\end{abstract}

\section{Introduction}

Historically, formation of non-sea salt sulfate aerosol in the atmosphere has been attributed to neutral binary nucleation of water and sulfuric acid. However, classical nucleation theory has not been completely successful at explaining atmospheric nucleation events (Weber et al., 1997; Clarke et al., 1998a; Weber et al., 1999; Weber et al., 2001a). Alternative pathways for sulfate aerosol formation have been suggested, including neutral ternary nucleation of water, sulfuric acid, and ammonia (Coffman and Hegg, 1995; Marti et al., 1997; Korhonen et al., 1999), and charged (ion-induced) nucleation of water and sulfuric acid (Dickinson, 1975; Raes and Janssens, 1985, 1993; Yu and Turco, 2000). Ions are likely aerosol precursors because they greatly stabilize small clusters with respect to evaporation. Atmospheric ions are produced mainly by galactic cosmic rays, and by radioactive decay of radon effusing from rocks and soils. Evidence for charged nucleation of aerosol includes direct observation of very large cluster ions in the upper troposphere (Eichkorn et al., 2002) and observations of bursts of intermediate ions followed by increases in ultrafine aerosol (Hõrrak et al., 1998). More recently, Laakso et al. (2004) explained the characteristics of particle formation events by preferential condensation of sulfuric acid onto negatively charged clusters and particles and/or by contribution of ion-induced nucleation to particle formation. In this work we investigate sulfate aerosol formation in the marine troposphere from neutral and charged binary nucleation, compare the potential of different regions and processes to produce new aerosol, discuss the implications for marine boundary layer and stratospheric aerosol populations, and the possible response of global cloud cover to variations in galactic cosmic ray intensity in the course of the decadal solar cycle.

Correspondence to: J. Kazil

(jan.kazil@noaa.gov)

Published by Copernicus GmbH on behalf of the European Geosciences Union. 
$\mathrm{SO}_{2} \mathrm{vmr}(\mathrm{ppt}), 925 \mathrm{hPa}$

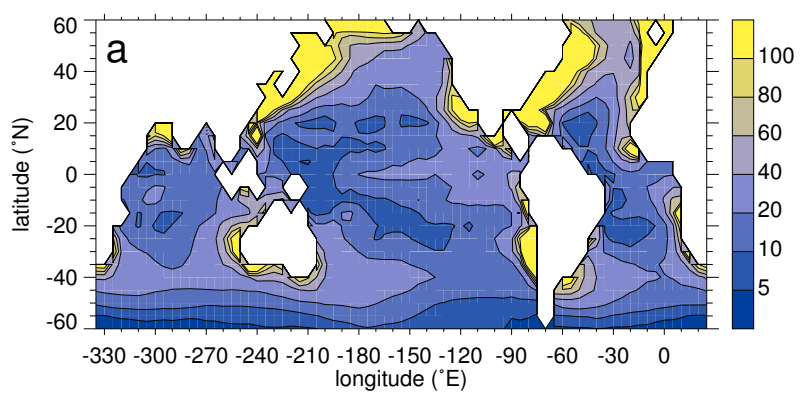

$\mathrm{SO}_{2}$ vmr (ppt) , $550 \mathrm{hPa}$

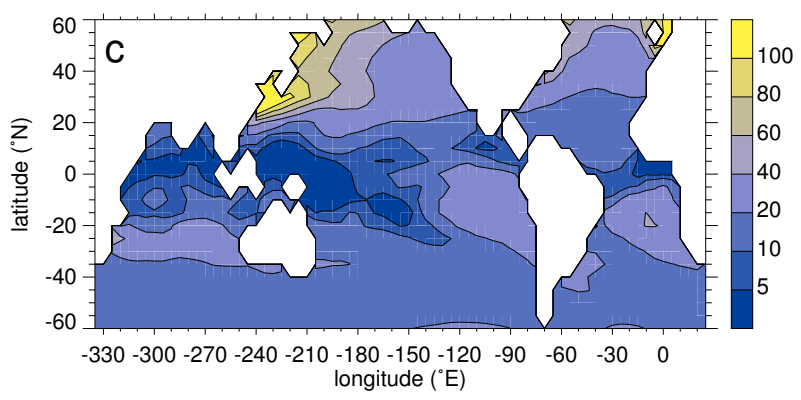

$\mathrm{SO}_{2} \mathrm{vmr}(\mathrm{ppt}), 700 \mathrm{hPa}$

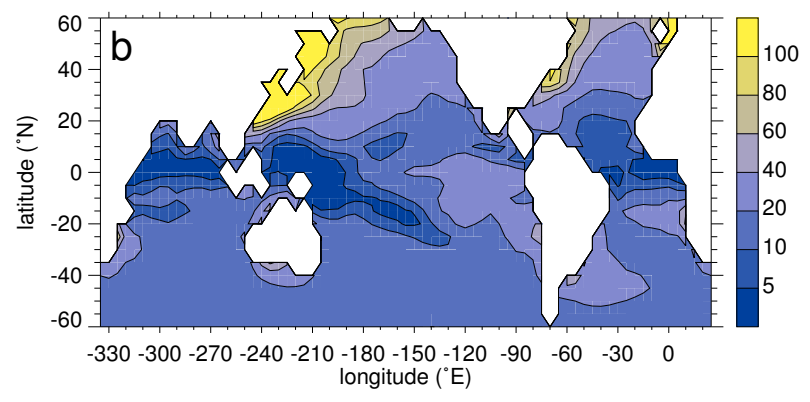

$\mathrm{SO}_{2} \operatorname{vmr}(\mathrm{ppt}), 300 \mathrm{hPa}$

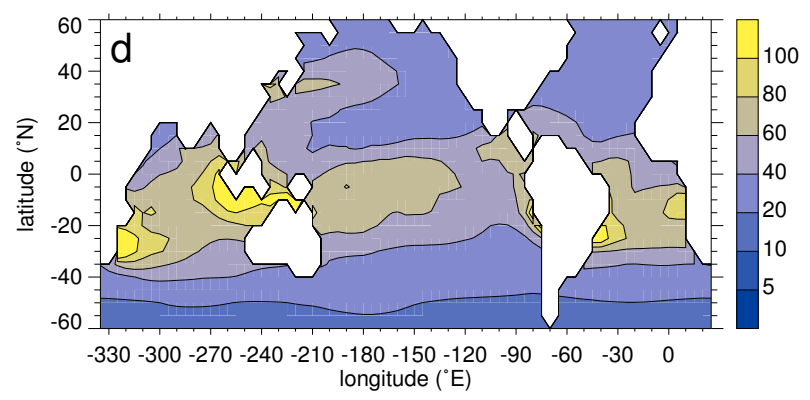

Fig. 1. Monthly mean $\mathrm{SO}_{2}$ volume mixing ratios for March, based on CCM 3 simulations of the global sulfur cycle (Barth et al., 2000).

\section{Model}

We use a hybrid kinetic-sectional model of neutral and charged sulfuric acid/water aerosol microphysics. This model is based on laboratory thermodynamic data for small charged $\mathrm{H}_{2} \mathrm{SO}_{4} / \mathrm{H}_{2} \mathrm{O}$ clusters (Curtius et al., 2001; Froyd and Lovejoy, 2003b), and on thermodynamic data for small neutral $\mathrm{H}_{2} \mathrm{SO}_{4} / \mathrm{H}_{2} \mathrm{O}$ clusters obtained from the modified liquid drop model, adjusted by Lovejoy et al. (2004) to reproduce laboratory observations (Ball et al., 1999). The thermodynamic data for large aerosol particles derive from $\mathrm{H}_{2} \mathrm{SO}_{4}$ and $\mathrm{H}_{2} \mathrm{O}$ vapor pressures calculated with the Aerosol Inorganics Model (Carslaw et al., 1995). The thermodynamic data for intermediate size particles are a smooth interpolation of the data from these sources. A detailed description of the model is given by Lovejoy et al. (2004).

We run this model on grids embedded into isobaric surfaces of the troposphere, excluding locations over continents and certain large islands. No interaction takes place between the grid points. Focusing on ocean areas reduces uncertainties in the model results: The diurnal temperature cycle is weaker over the oceans than over land (Seidel et al., 2005), hence using daily long term mean temperatures yields a smaller error over oceans compared with land. Oceans are also only weak sources of radon (Schery and Huang, 2004) and of ammonia (Dentener and Crutzen, 1994) compared with land masses, and hence neglecting their effect on ion production and nucleation is more appropriate over the oceans than over continents. Nonetheless, ammonia and radon are transported from land over the oceans where they can aid nucleation, which we do not account for.

For this study, we chose the $925,700,550$, and $300 \mathrm{hPa}$ surfaces, and grids with a horizontal resolution of $5^{\circ}$, covering all longitudes and the latitudes between $60^{\circ} \mathrm{S}$ and $60^{\circ} \mathrm{N}$. The model thus covers $64 \%$ of the globe, or $90 \%$ of the oceans. We start the model at sunrise with a zero initial aerosol concentration and compute the aerosol size distribution at given times from the $\mathrm{SO}_{2}$ concentration, the concentration of the hydroxyl radical $\mathrm{OH}$, ionization rate, relative humidity, temperature, and pressure. The production rate of sulfuric acid is calculated under the assumption that the reaction $\mathrm{SO}_{2}+\mathrm{OH}$ is the rate-limiting step of the oxidation chain $\mathrm{SO}_{2} \rightarrow \mathrm{H}_{2} \mathrm{SO}_{4}$ (Lovejoy et al., 1996).

\section{Input data}

\section{$3.1 \quad \mathrm{SO}_{2}$}

$\mathrm{SO}_{2}$ concentrations are monthly means averaged over a 3 year period simulation of the global sulfur cycle by the Community Climate Model version 3 (CCM3) (Barth et al., 2000). In the CCM3 simulations sources of $\mathrm{SO}_{2}$ are anthropogenic emissions and gas-phase oxidation of dimethyl 
$[\mathrm{OH}]\left(\mathrm{cm}^{-3}\right), 925 \mathrm{hPa}$

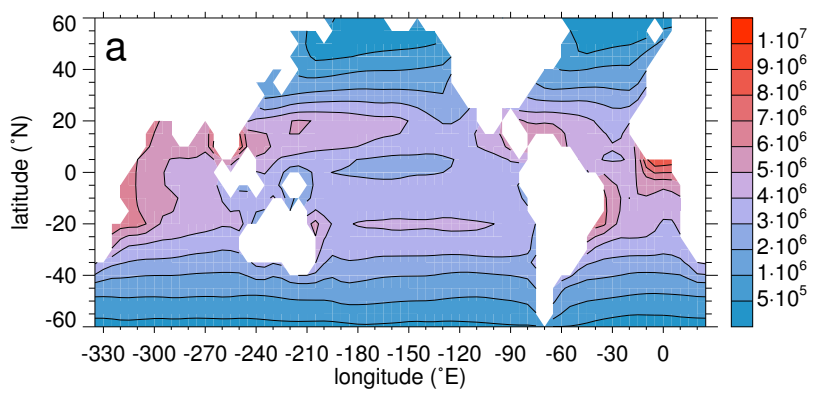

$[\mathrm{OH}]\left(\mathrm{cm}^{-3}\right), 550 \mathrm{hPa}$

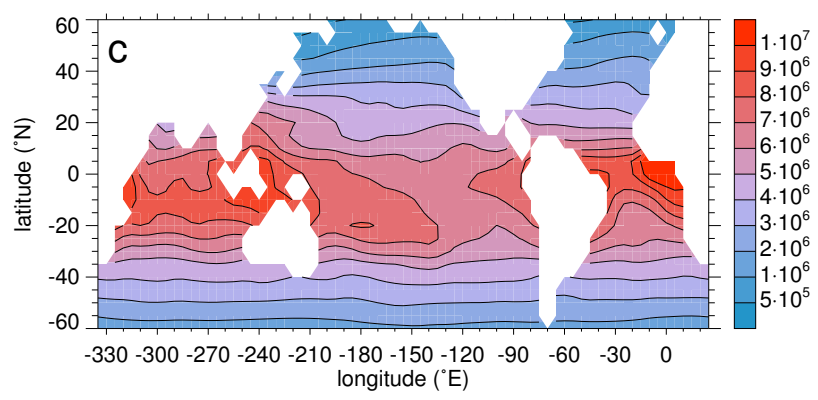

$[\mathrm{OH}]\left(\mathrm{cm}^{-3}\right), 700 \mathrm{hPa}$

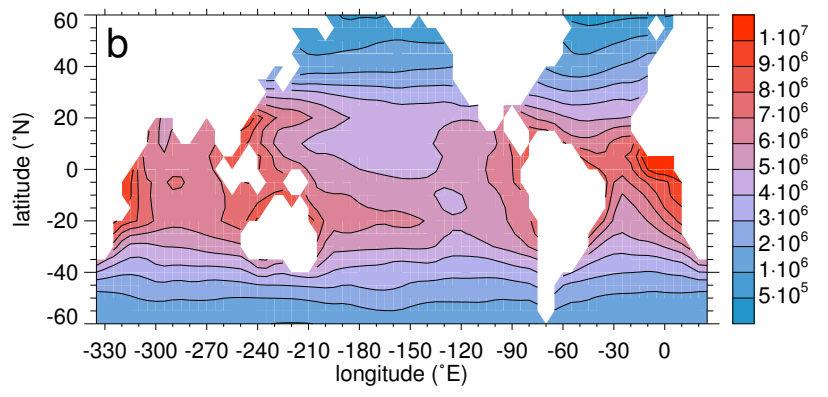

$[\mathrm{OH}]\left(\mathrm{cm}^{-3}\right), 300 \mathrm{hPa}$

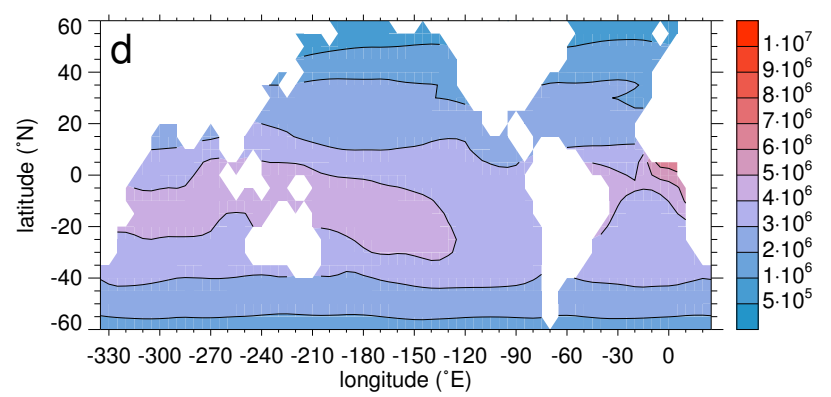

Fig. 2. 21 March noon OH concentrations, based on the photochemical model of Spivakovsky et al. (2000).

sulfide (DMS), while $\mathrm{SO}_{2}$ sinks are gas and aqueous reactions forming sulfate, and dry and wet deposition. Both $\mathrm{SO}_{2}$ and DMS emissions are patchy corresponding to particular industrial sources or oceanic upwelling regions, respectively. Figure 1 shows the resulting monthly mean $\mathrm{SO}_{2}$ distribution for March. Over the oceans, the largest $\mathrm{SO}_{2}$ concentrations emerge near continents, especially at lower altitudes. The high concentrations on the eastern edge of Asia and North America and on the western edge of Europe result from human activity, while the high concentrations at low altitudes near the west coast of South America and Africa are from DMS (Fig. 1a). Isentropic and convective transport move $\mathrm{SO}_{2}$ and DMS to higher altitudes where $\mathrm{SO}_{2}$ is found mostly in the tropics (Fig. 1d). An evaluation of the $\mathrm{SO}_{2}$ concentrations with measurements found that modeled $\mathrm{SO}_{2}$ agreed reasonably with observations but showed some overprediction of $\mathrm{SO}_{2}$ in regions influenced by human activity (Barth et al., 2000). The annual cycle of lower-tropospheric, global $\mathrm{SO}_{2}$ peaks in December and reaches a minimum in June following the emission pattern of Europe and Asia (Rasch et al., 2000). At high altitudes the annual cycle is very weak and has a peak in summer.

\section{$3.2 \mathrm{OH}$}

We parameterize the $\mathrm{OH}$ diurnal cycle as a half sine centered around noon, while setting the $\mathrm{OH}$ concentration to zero dur- ing nighttime. The $24 \mathrm{~h}$ mean of the $\mathrm{OH}$ diurnal cycle is set to the monthly mean $\mathrm{OH}$ concentrations from the global photochemical model of Spivakovsky et al. (2000). Figure 2 shows the noon $\mathrm{OH}$ concentration for 21 March.

\subsection{GCR ionization rate}

Galactic cosmic rays (GCR) are the main source of ions in the troposphere above the oceans. Upon entering the Earth atmosphere, primary cosmic ray particles, mostly hydrogen and helium nuclei, collide with atmospheric gas molecules and initiate a cascade of nuclear and electromagnetic reactions producing secondary cosmic rays. The computer code PLOTINUS (Programmed Linear Operator for the Transport of NUclear Showers) (O'Brien, 2005) treats each component of the secondary cosmic radiation propagating through the atmosphere, accounting for the nuclear and electromagnetic interactions, and computes the flux of the secondary particles from the primary GCR spectrum. The ion production rate at a given location is computed from the particle fluxes and the atmospheric mass density at that location, and from the ionization cross sections of the atmospheric constituents.

PLOTINUS output has been verified by comparison with observed particle fluxes, such as those tabulated by Allkofer and Grieder (1984), and quite successfully reproduces the available measurements of cosmic ray ionization in the atmosphere: Fig. 3 compares the calculated GCR ionization 

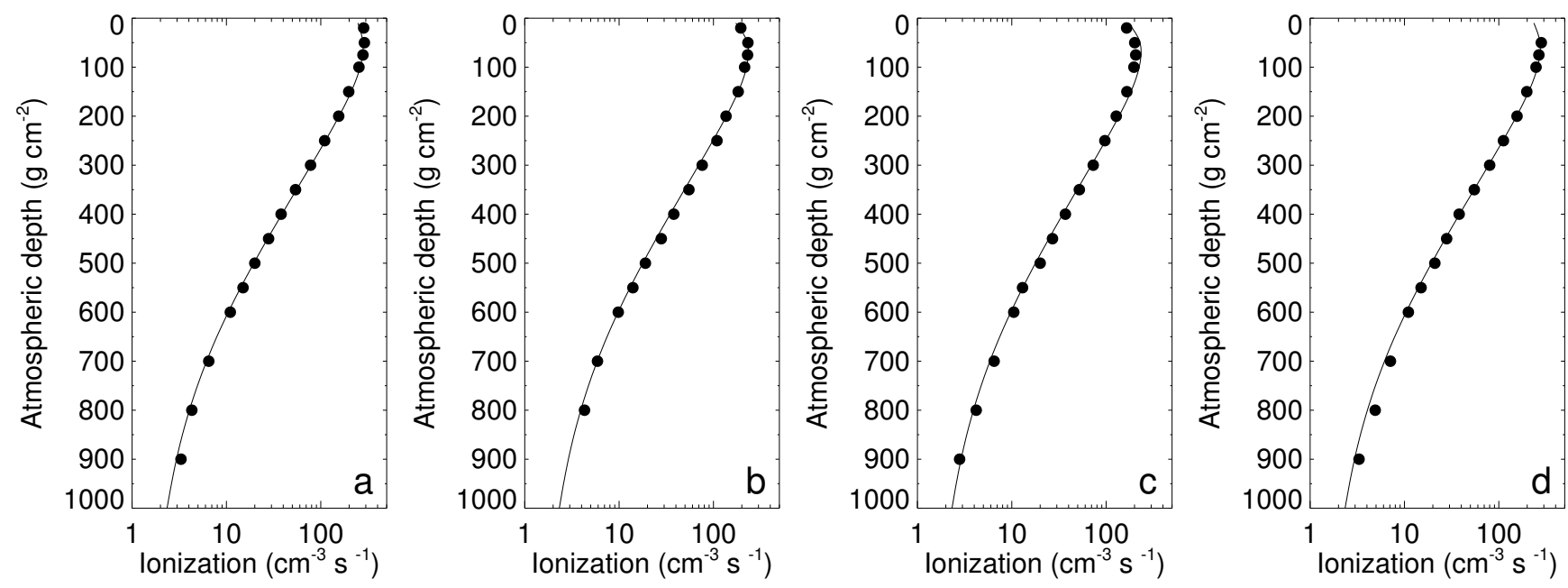

Fig. 3. Ionization rate profiles measured by Lowder et al. (1972) (dots) and calculated with the code of O'Brien (2005) (solid lines) over (a) Durham, NH in May 1969, (b) Palestine, TX in November 1969, (c) Palestine, TX in June 1970, and (d) Sioux City, IA in April 1970. The ionization rate is given as number of ion pairs produced per second in one $\mathrm{cm}^{3}$ of air at $273.15 \mathrm{~K}$ and $1013.25 \mathrm{hPa}$. The IGRF 1965 and 1970 epochs for the years 1969 and 1970, respectively, and the cosmic ray modulation parameter for the time of the measurements have been used to calculate these ionization profiles.
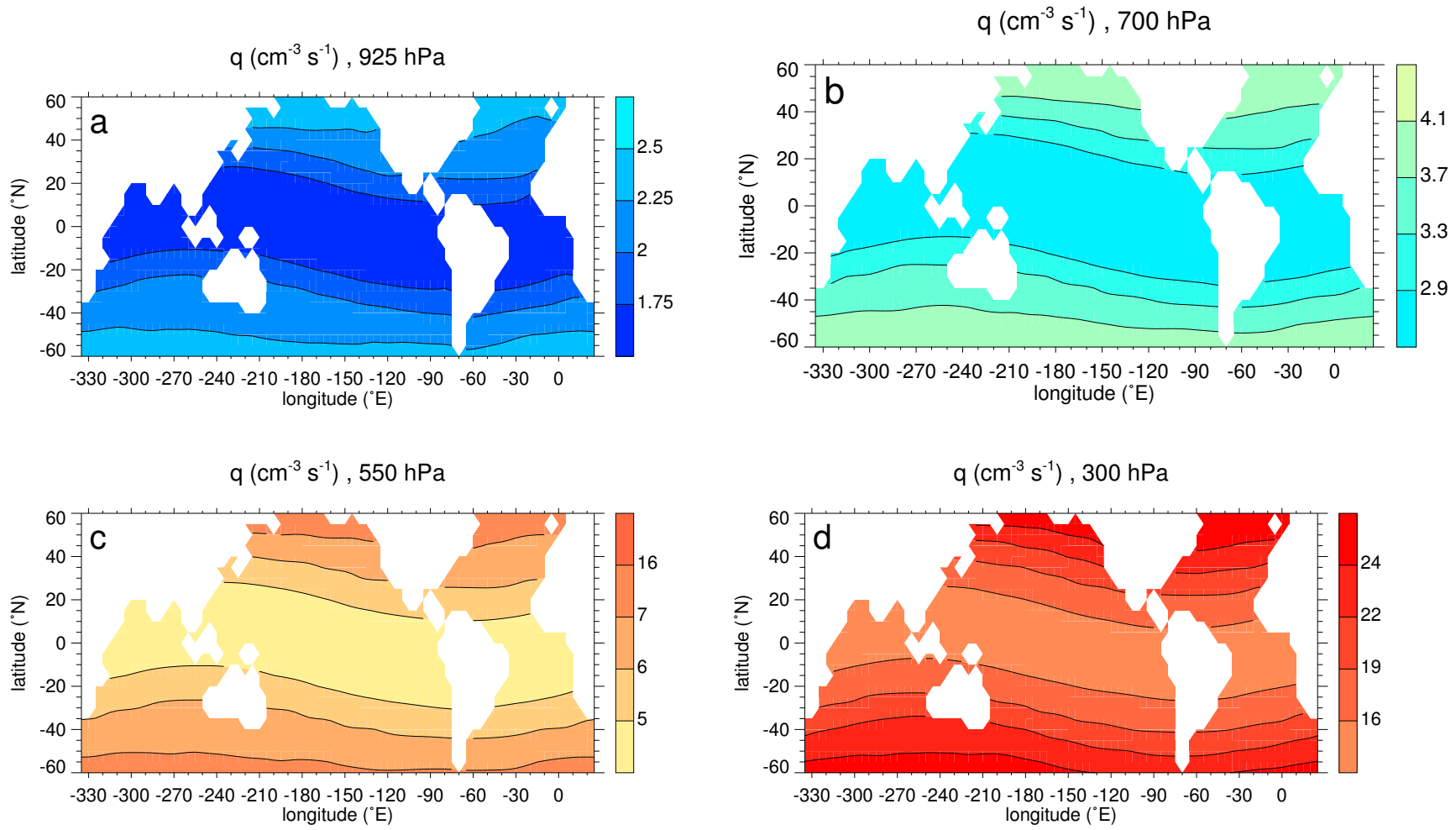

Fig. 4. Galactic cosmic ray ionization rate calculated with the code of O'Brien (2005) for solar maximum. The ionization rate is given as number of ion pairs produced per second in one $\mathrm{cm}^{3}$ of ambient air. 


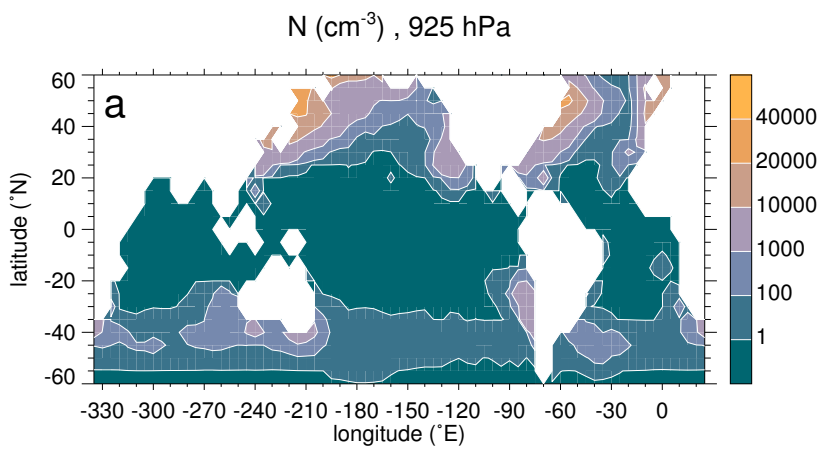

$\mathrm{N}\left(\mathrm{cm}^{-3}\right), 550 \mathrm{hPa}$

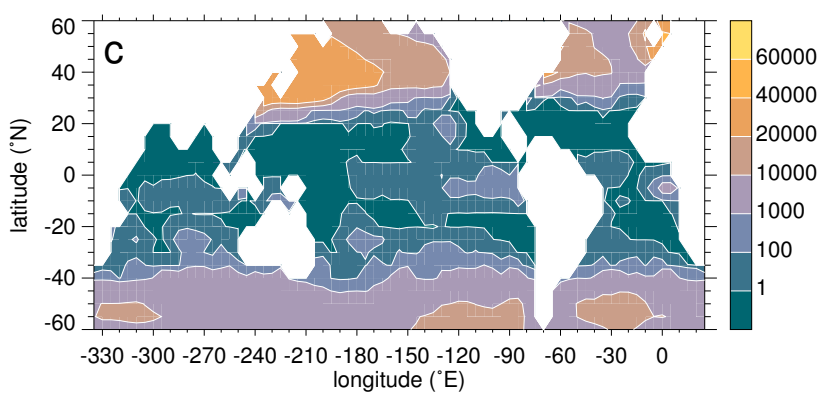

$\mathrm{N}\left(\mathrm{cm}^{-3}\right), 700 \mathrm{hPa}$

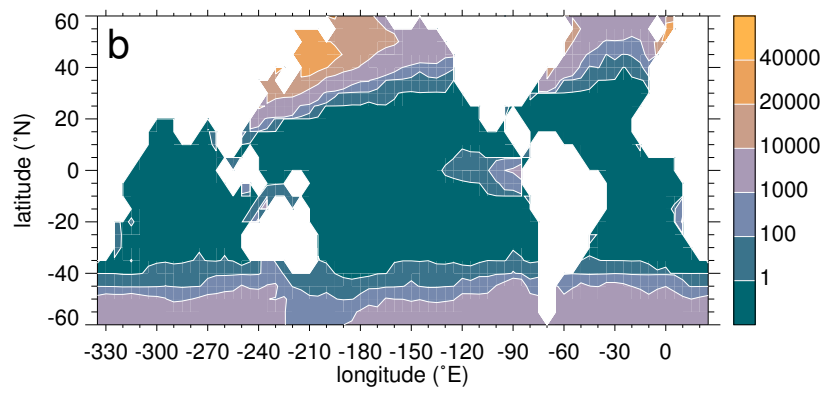

$\mathrm{N}\left(\mathrm{cm}^{-3}\right), 300 \mathrm{hPa}$

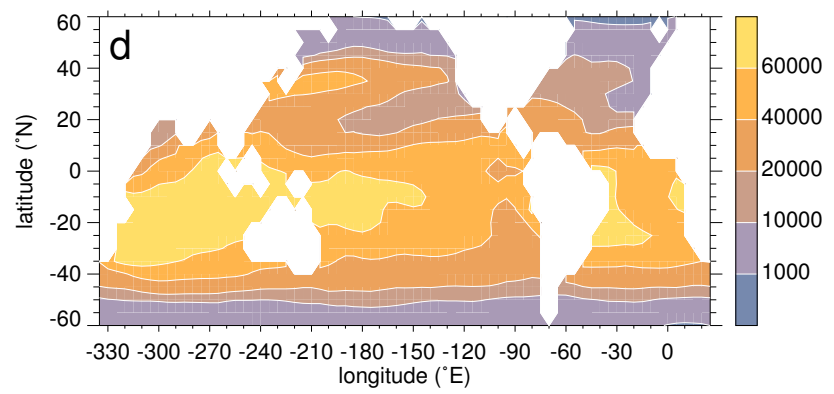

Fig. 5. Concentration of supercritical aerosol calculated for noon of 21 March, using the solar maximum ionization rates of Fig. 4.

profiles with measurements of Lowder et al. (1972) at different locations and dates. GCR intensity and ionization are anticorrelated with the decadal solar cycle (Forbush, 1954; Neher and Forbush, 1958). In this work, we use PLOTINUS and the International Geomagnetic Reference Field (IGRF) 1990 epoch and the cosmic ray modulation parameter for June 1990 to calculate the ionization rates at solar maximum, and the IGRF 1995 epoch and the cosmic ray modulation parameter for January 1998 to calculate the ionization rates at solar minimum. We use the GEOPACK 2003 software suite (Tsyganenko, 2003) to calculate the orientation of the Earth magnetic dipole for a given year and the day of the year and the corresponding transformation between geographic and geomagnetic coordinates. Figure 4 shows the resulting GCR ionization rates for solar maximum at the four modeled pressure levels.

\subsection{Temperature and relative humidity}

We use temperature and relative humidity NCEP/NCAR reanalysis data provided by the NOAA-CIRES Climate Diagnostics Center (2004). These data are based on assimilation of observations starting in 1948 by a global atmosphere model and represent the daily mean temperature and relative humidity averaged between 1948 and 2005 .

\section{Results}

\subsection{Aerosol production}

We start our model with no preexisting aerosol, hence all sulfuric acid in the gas phase contributes to the formation and growth of new particles, instead of condensing onto any preexisting aerosol. The resulting aerosol concentrations are thus an upper limit in the adopted conditions. Figure 5 shows the concentration of supercritical aerosol (particles larger than the neutral critical cluster) calculated with our model for noon of 21 March, using solar maximum ionization rates. These aerosol concentrations were obtained by integrating the aerosol size distribution starting at particles that contain one $\mathrm{H}_{2} \mathrm{SO}_{4}$ molecule more than the neutral critical cluster, up to about $900 \mathrm{~nm}$ in diameter. However, no $900 \mathrm{~nm}$ particles form in the $24 \mathrm{~h}$ of our simulations, and the peak of the freshly nucleated aerosol size distribution is typically located between 2 and $10 \mathrm{~nm}$ in diameter at noon, depending on temperature, $\mathrm{RH}$, and on the availability of gas phase $\mathrm{H}_{2} \mathrm{SO}_{4}$.

Over the tropical oceans, aerosol production is negligible in the lower troposphere (Figs. 5 a, b), where aerosol concentrations remain below $1 \mathrm{~cm}^{-3}$ over most of the area. Slightly higher, but nonetheless weak aerosol production occurs in the tropical middle troposphere (Fig. 5c). High aerosol concentrations arise at mid-latitudes in the lower and middle troposphere, in particular downwind of industrial regions of the 
$\left[\mathrm{H}_{2} \mathrm{SO}_{4}\right]\left(\mathrm{cm}^{-3}\right), 925 \mathrm{hPa}$

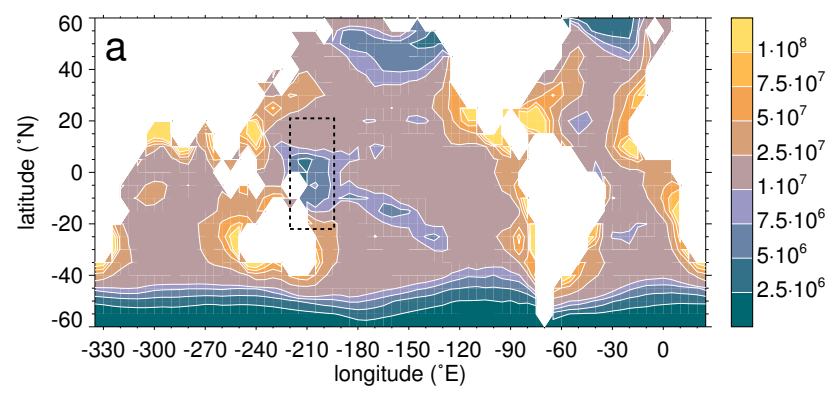

$\left[\mathrm{H}_{2} \mathrm{SO}_{4}\right]\left(\mathrm{cm}^{-3}\right), 550 \mathrm{hPa}$

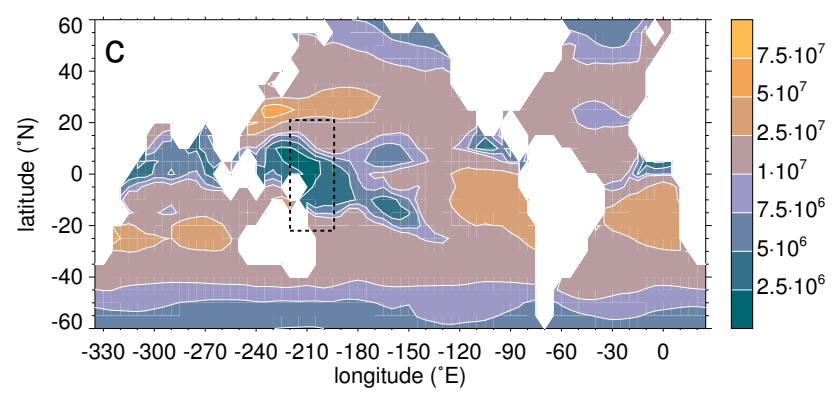

$\left[\mathrm{H}_{2} \mathrm{SO}_{4}\right]\left(\mathrm{cm}^{-3}\right), 700 \mathrm{hPa}$

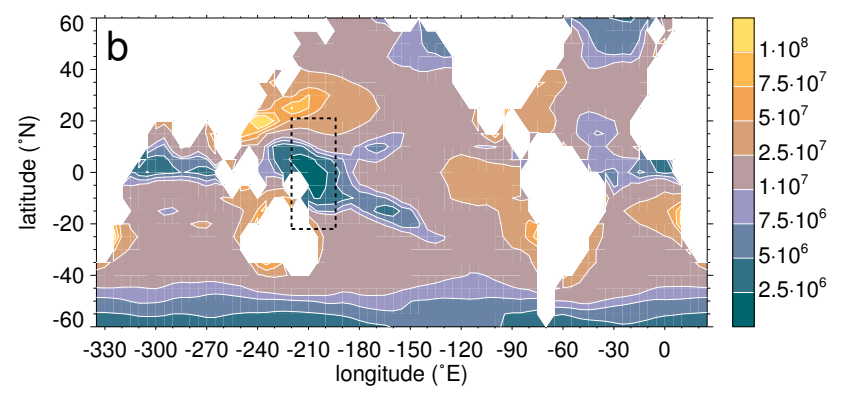

$\left[\mathrm{H}_{2} \mathrm{SO}_{4}\right]\left(\mathrm{cm}^{-3}\right), 300 \mathrm{hPa}$

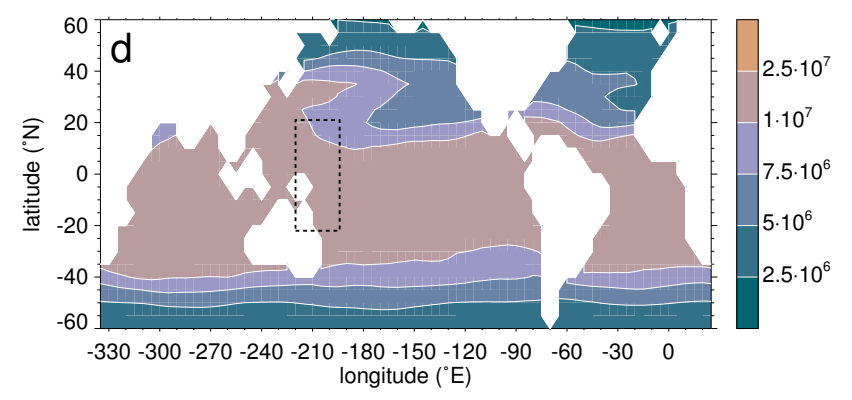

Fig. 6. $\mathrm{H}_{2} \mathrm{SO}_{4}$ concentration calculated for noon of 21 March, using the solar maximum ionization rates of Fig. 4. Average values for the outlined region are given in Table 1 . Sulfuric acid concentrations observed in this region in February and March are given by Weber et al. (2001b).

northern hemisphere (Figs. 5a, b, c). The highest aerosol production, however, occurs in the upper troposphere (at the $300 \mathrm{hPa}$ level of our simulations), most notably above the intertropical convergence zone (ITCZ) (Fig. 5d).

The aerosol concentration patterns seen in Fig. 5 can be readily explained with the distribution of $\mathrm{SO}_{2}$ (Fig. 1) and temperature: Low $\mathrm{SO}_{2}$ concentrations and warm conditions in the low and middle troposphere in the tropics hamper nucleation and aerosol growth. Prevailing westerlies transport $\mathrm{SO}_{2}$ in the northern hemisphere and DMS in the southern hemisphere eastwards, thus enabling aerosol formation in the mid-latitudes of the lower and middle troposphere. Low temperatures and high concentrations of $\mathrm{SO}_{2}$ in the upper troposphere facilitate a powerful particle formation, especially above the ITCZ, where convection is strongest and $\mathrm{SO}_{2}$ concentrations are relatively high.

Aerosol concentrations depend not only on $\mathrm{SO}_{2}$ and $\mathrm{OH}$ concentrations, but also on day length, and on the distributions of relative humidity and temperature. In June, September, and December (not shown), similar patterns in the distribution of supercritical aerosol concentrations in the lower and middle troposphere emerge from our simulations: Very low values prevail at tropical latitudes, while higher latitudes exhibit larger aerosol concentrations. At $300 \mathrm{hPa}$, the aerosol peak concentration follows the ITCZ and the $\mathrm{SO}_{2}$ distribution, and is shifted towards the northern hemisphere in June and September, and towards the southern hemisphere in March and December. In order to compare the contribution from neutral and charged nucleation, we repeated our model runs with ionization switched off. Aerosol concentrations reached only negligible values in these runs, at most a few percent of those resulting from charged nucleation. The highest contribution to aerosol production from neutral binary nucleation occurred at the $300 \mathrm{hPa}$ level, owing to the low temperatures in the upper troposphere.

\section{$4.2 \mathrm{H}_{2} \mathrm{SO}_{4}$}

Figure 6 shows the concentration of gas phase sulfuric acid for noon of 21 March, calculated with solar maximum ionization rates. Over large ocean areas, the $\mathrm{H}_{2} \mathrm{SO}_{4}$ concentrations assume values between $10^{7}$ and $2.5 \cdot 10^{7} \mathrm{~cm}^{-3}$. Elevated values $\left(>10^{8} \mathrm{~cm}^{-3}\right)$ occur in coastal areas with high $\mathrm{SO}_{2}$ (Fig. 1) and $\mathrm{OH}$ concentrations (Fig. 2). Depressed values are seen in unpolluted areas at higher latitudes, where $\mathrm{OH}$ concentrations are low due to larger solar zenith angles.

In the the equatorial western Pacific, low noon sulfuric acid concentrations in the lower and middle troposphere (Figs. 6a-c) contrast with higher concentrations the upper troposphere (Fig. 6d). This distribution is due to frequent 
convective transport of $\mathrm{SO}_{2}$ from the lower to the upper troposphere over the western Pacific warm pool (Fig. 1). The opposite pattern is seen in a collection of sulfuric acid measurements (Weber et al., 2001b) acquired in the region outlined in Fig. 6, which show a decrease of sulfuric acid concentrations from values between $10^{6}$ and $10^{8} \mathrm{~cm}^{-3}$ near the ocean surface to values around $10^{6} \mathrm{~cm}^{-3}$ in the upper troposphere. In our simulations, this decrease with altitude is established later in the day (Table 1), owing to the accumulation of sulfuric acid in the lower and middle troposphere where particle concentrations (Figs. 5a-c) and thus gas phase sulfuric acid loss are low, and due to the loss of sulfuric acid onto the numerous freshly nucleated particles in the upper troposphere (Fig. 5d). Thus the formation of ultrafine particles in the upper troposphere shapes the sulfuric acid altitude profile as seen in the measurements of Weber et al. (2001b), who also report an increase in ultrafine particle concentrations with altitude. This comparison must be taken with a grain of salt, as the conditions at the time of the measurements may have differed from those in our simulations, and as our model does not account for a number of relevant processes.

\subsection{Response of aerosol production to variations in GCR ionization}

We ran simulations using GCR ionization rates for solar maximum and solar minimum and otherwise identical conditions. This approach allows us to assess the idealized response of aerosol nucleation to the variation of GCR ionization over the solar cycle. In reality, variability of ambient conditions and of aerosol concentrations unrelated to the solar cycle may render a solar cycle signal in aerosol nucleation at a given time and location undetectable. In order to ensure antisymmetry and convergence, we define the operator $\Delta_{\mathrm{GCR}}$ giving the response of a quantity, such as the supercritical aerosol concentration $N$, to the increase in GCR ionization $q$ from solar maximum to minimum as

$\Delta_{\mathrm{GCR}} N \doteq \frac{N\left(q_{\min }\right)-N\left(q_{\max }\right)}{\max \left(\left|N\left(q_{\max }\right)\right|,\left|N\left(q_{\min }\right)\right|\right)}$

where $q_{\min }$ and $q_{\max }$ are ionization rates at solar minimum and solar maximum, respectively. We will refer to a positive response (correlation) of $N$ to GCR ionization if $\Delta_{\mathrm{GCR}} N$ is $>0$, and to a negative response (anticorrelation) if $\Delta_{\mathrm{GCR}} N<0$. In warm conditions, or at low $\mathrm{H}_{2} \mathrm{SO}_{4}$ production, only few aerosol particles may grow to supercritical sizes. As our model is started with a zero aerosol concentration, model bins otherwise containing supercritical aerosol particles may remain empty. Numerical errors will produce small random aerosol concentrations in these "empty" bins, and comparing supercritical aerosol concentrations from two model runs may lead to random differences. These numerical errors are easily detected when they result in $\left|\Delta_{\mathrm{GCR}} N\right|>\left|\Delta_{\mathrm{GCR}} q\right|$, but they would go unnoticed for $\left|\Delta_{\mathrm{GCR}} N\right|<\left|\Delta_{\mathrm{GCR}} q\right|$. We
Table 1. Simulated gas phase $\mathrm{H}_{2} \mathrm{SO}_{4}$ concentrations $\left(\mathrm{cm}^{-3}\right)$ for $21 \mathrm{March}$, averaged over the western Pacific warm pool region between $22^{\circ} \mathrm{S}$ and $21^{\circ} \mathrm{N}$, and between $220^{\circ}$ and $194^{\circ} \mathrm{W}$, outlined in Fig. 6.

\begin{tabular}{lllll}
\hline & $12 \mathrm{~h}$ & $15 \mathrm{~h}$ & $18 \mathrm{~h}$ & $24 \mathrm{~h}$ \\
\hline $300 \mathrm{hPa}$ & $1.2 \cdot 10^{7}$ & $5.3 \cdot 10^{6}$ & $1.0 \cdot 10^{6}$ & $5.8 \cdot 10^{3}$ \\
$550 \mathrm{hPa}$ & $9.3 \cdot 10^{6}$ & $1.6 \cdot 10^{7}$ & $1.8 \cdot 10^{7}$ & $1.6 \cdot 10^{7}$ \\
$700 \mathrm{hPa}$ & $1.5 \cdot 10^{7}$ & $2.5 \cdot 10^{7}$ & $2.6 \cdot 10^{7}$ & $2.4 \cdot 10^{7}$ \\
$925 \mathrm{hPa}$ & $1.3 \cdot 10^{7}$ & $2.2 \cdot 10^{7}$ & $2.4 \cdot 10^{7}$ & $2.2 \cdot 10^{7}$ \\
\hline
\end{tabular}

resolve this difficulty by disregarding $\Delta_{\mathrm{GCR}} N$ at locations where $N<0.001 \mathrm{~cm}^{-3}$.

Figure 7 shows $\Delta_{\mathrm{GCR}} N$ at noon of 21 March at the four modeled pressure levels. In the lower troposphere (Figs. 7a, b), the supercritical aerosol concentrations remain below the $0.001 \mathrm{~cm}^{-3}$ threshold (gray areas) over the warmest regions of the tropical oceans. Positive response (red) prevails outside the tropics in the lower and middle troposphere, with the highest positive response downwind of industrial regions of the northern hemisphere (Figs. 7a, b, c). Negative response (blue) occurs mainly at higher latitudes, except for isolated locations in the tropical middle troposphere (Fig. 7c).

The spatial patterns in Fig. 7 can be explained as follows: Sulfuric acid and ion concentrations determine the production rate of supercritical clusters (Kazil and Lovejoy, 2004): High $\mathrm{H}_{2} \mathrm{SO}_{4}$ concentrations enable a fast growth of the charged subcritical clusters relative to their loss by neutralization, and an increase in ionization increases the formation rate of supercritical particles (correlation regime). Conversely, at low $\mathrm{H}_{2} \mathrm{SO}_{4}$ concentrations, with slow cluster growth, an increase in ionization enhances loss of charged subcritical clusters through neutralization, reducing the formation rate of supercritical particles (anticorrelation regime). The response of supercritical aerosol to GCR ionization in Fig. 7 is therefore positive where $\mathrm{H}_{2} \mathrm{SO}_{4}$ production and concentrations are sufficiently high, such as in regions with high anthropogenic $\mathrm{SO}_{2}$ concentrations in the northern hemisphere, or in regions with high $\mathrm{SO}_{2}$ concentrations from DMS in the southern hemisphere. In regions with low $\mathrm{SO}_{2}$ concentrations and high ionization, the response is negative.

However, $\mathrm{H}_{2} \mathrm{SO}_{4}$ production has a diurnal cycle. Figure 8 shows the diurnal evolution of $\mathrm{H}_{2} \mathrm{SO}_{4}$ concentration and the resulting response of supercritical aerosol $\Delta_{\mathrm{GCR}} N$ for a given location. The $\mathrm{H}_{2} \mathrm{SO}_{4}$ concentration increases from low values in the morning, as production increases, reaches a peak after midday, and decreases in the afternoon due to declining production and enhanced loss onto particles. $\Delta_{\mathrm{GCR}} N$ follows the $\mathrm{H}_{2} \mathrm{SO}_{4}$ concentration with a delay: In the morning, at low $\left[\mathrm{H}_{2} \mathrm{SO}_{4}\right]$, nucleation takes place in the anticorrelation regime, and $\Delta_{\mathrm{GCR}} N$ is negative. As $\left[\mathrm{H}_{2} \mathrm{SO}_{4}\right]$ increases in the 

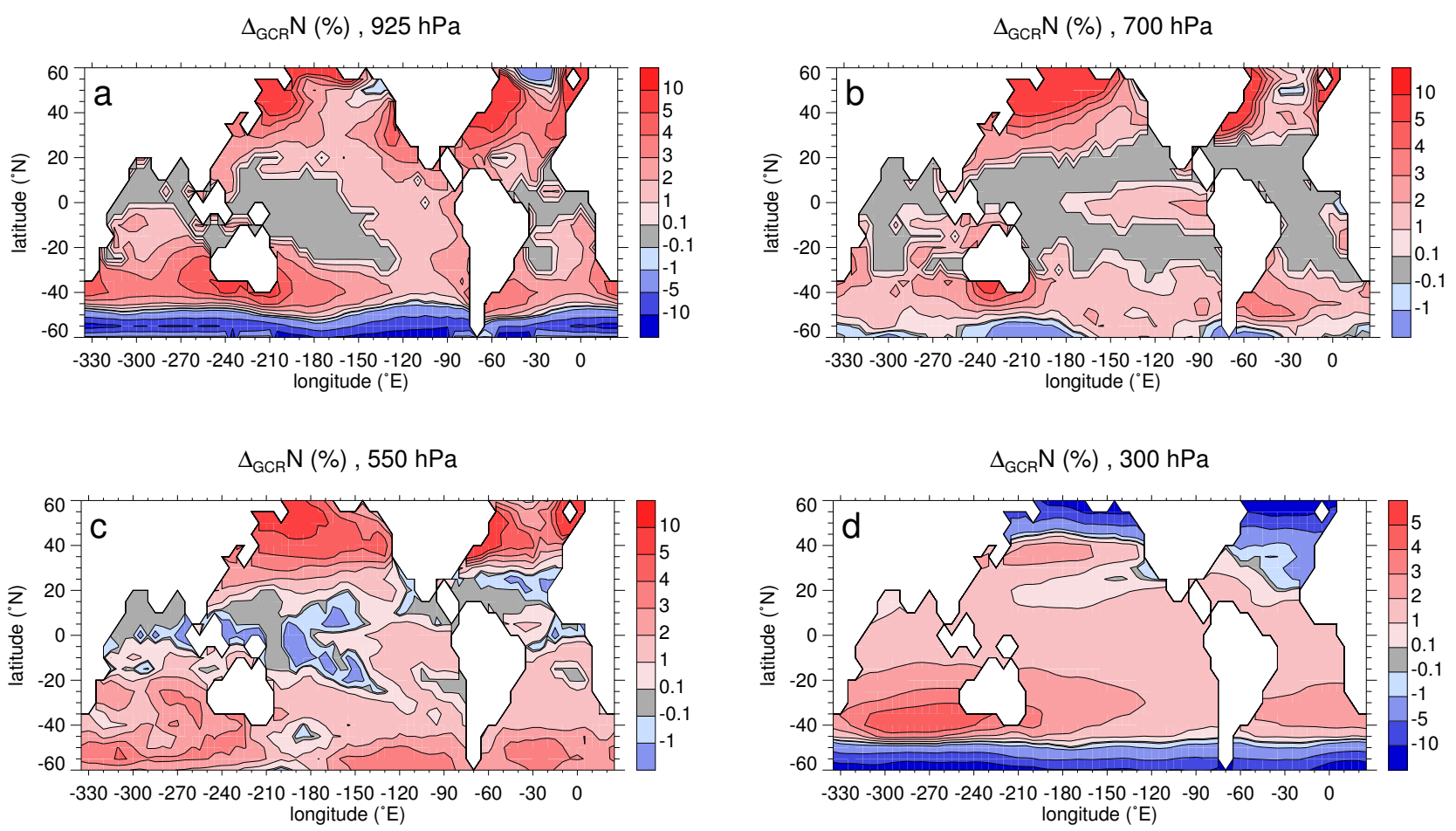

Fig. 7. Response of the supercritical aerosol concentration to the change in GCR ionization from solar maximum to minimum, calculated for noon of 21 March. Areas with $\Delta_{\mathrm{GCR}} N>0$ are colored red, areas with $\Delta_{\mathrm{GCR}} N<0$ blue. Areas with aerosol concentrations below $0.001 \mathrm{~cm}{ }^{-3}$, or where $\left|\Delta_{\mathrm{GCR}} N\right|<0.1 \%$ are colored gray.

\section{$700 \mathrm{hPa}$, March $21,50^{\circ} \mathrm{E} 55^{\circ} \mathrm{S}$}

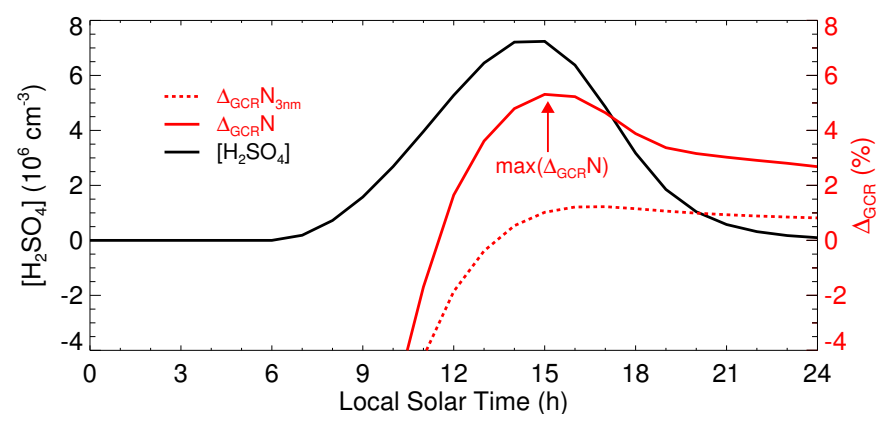

Fig. 8. Gas phase concentration of $\mathrm{H}_{2} \mathrm{SO}_{4}$ for $21 \mathrm{March}$ at $700 \mathrm{hPa}$, calculated with solar maximum ionization rates, and the response of supercritical aerosol $\left(\Delta_{\mathrm{GCR}} N\right)$ and of $>3 \mathrm{~nm}$ diameter aerosol $\left(\Delta_{\mathrm{GCR}} N_{3 \mathrm{~nm}}\right)$ concentrations to GCR ionization.

course of the day, nucleation enters the correlation regime, and $\Delta_{\mathrm{GCR}} N$ turns positive shortly before noon. It reaches a peak in the afternoon and declines thereafter due to coagulation, which, being a second-order process, reduces higher aerosol concentrations more efficiently than lesser ones. The response $\Delta_{\mathrm{GCR}} N_{3 \mathrm{~m}}$ of aerosol particles exceeding $3 \mathrm{~nm}$ in diameter remains below $\Delta_{\mathrm{GCR}} N$ at all times: Larger particles form earlier in the day compared with smaller particles, and therefore closer to or further in the anticorrelation regime.

Since our model starts with no preexisting aerosol, sulfuric acid concentrations are limited only by loss to freshly nucleated aerosol, which hence forms in the most favorable conditions for a positive response to an increase in ionization. Extending the model run by another day e.g. would yield a smaller peak in $\Delta_{\mathrm{GCR}} N$ on the second day due to condensation of $\mathrm{H}_{2} \mathrm{SO}_{4}$ onto aerosol that formed during the first day. We therefore argue that in the given conditions, the peak of the supercritical aerosol response $\max \left(\Delta_{\mathrm{GCR}} N\right)$ as seen in Fig. 8 represents an upper limit to the response of freshly nucleated, stable aerosol concentrations to the increase of GCR ionization from solar maximum to minimum. Table 2 gives the spatially weighted average $\overline{\max \left(\Delta_{\mathrm{GCR}} N\right)}$ over the model area on the four modeled dates and pressure levels. The averages are similar for the lower and middle troposphere $(925,700$, and $550 \mathrm{hPa}$ levels), except for June: This month is characterized by a minimum in the annual $\mathrm{SO}_{2}$ cycle, and by short daylight periods over a large ocean area (in the southern hemisphere), resulting in reduced $\mathrm{H}_{2} \mathrm{SO}_{4}$ production and in aerosol nucleation in or near the anticorrelation regime. At $300 \mathrm{hPa}$, 
GCR ionization is stronger compared with the lower levels (see Fig. 4), and nucleation takes place closer to the anticorrelation regime despite abundant $\mathrm{SO}_{2}$ (see Fig. 1d), resulting in lower values of $\overline{\max \left(\Delta_{\mathrm{GCR}} N\right)}$.

\section{Discussion}

\subsection{Sources of marine boundary layer aerosol}

Sources of marine boundary layer (MBL) aerosol include ejection of sea salt particles from the ocean surface, entrainment of aerosol particles from the free troposphere, and in situ nucleation. However, condensation of sulfuric acid onto preexisting aerosol is energetically more efficient than nucleation, and typical MBL (dry) aerosol surface area concentrations of $20-100 \mu^{2} \mathrm{~cm}^{-3}$ (Covert et al., 1996) do not allow gas-phase sulfuric acid to attain concentrations required for nucleation. Accordingly, nucleation occurs in the MBL only infrequently, e.g. when aerosol surface area is reduced by precipitation, and does not contribute appreciably to long-term average MBL aerosol concentrations (Katoshevski et al., 1999). Hence most of the non-sea salt sulfate aerosol in the MBL must originate from other locations. Indeed, model studies (Raes and Van Dingenen, 1992; Raes, 1995) and observations (Clarke et al., 1996; Raes et al., 1997; Bates et al., 1998) have explained MBL aerosol concentrations with entrainment from the free troposphere. Katoshevski et al. (1999) even concluded that MBL aerosol number concentration is dominated by aerosol from the free troposphere under virtually all conditions.

Free tropospheric aerosol production is associated with clouds: Hegg et al. (1990) reported significantly enhanced concentrations of ultrafine particles $(<10 \mathrm{~nm}$ in diameter) near the tops of marine stratiform clouds. They suggested that clouds may be a necessary precursor of aerosol in the marine atmosphere, implicating a feedback loop of aerosol production by clouds and cloud formation from aerosol. Observations of very high concentrations of ultrafine particles in the outflow regions of convective clouds (Clarke, 1993; Clarke et al., 1998b, 1999; Wang et al., 2000; Twohy et al., 2002) led to the proposition that in the tropics, the MBL aerosol population is maintained by deep convection lifting boundary layer air rich in aerosol precursor gases into the upper troposphere, initiating nucleation aloft (Raes et al., 1993; Clarke, 1993; Clarke et al., 1998b). Preexisting aerosol surface area preventing nucleation in the air lifted from the MBL would be reduced in the updraft by cloud scavenging. The newly formed particles would slowly descend from the upper troposphere in the subsiding air motion compensating convection, grow, and eventually enter the MBL where they would replenish the aerosol population.

Model simulations support aerosol production by clouds: Using a mesoscale model at subtropical and mid-latitudes, Liu et al. (2001) found significant aerosol nucleation occur-
Table 2. $\overline{\max \left(\Delta_{\mathrm{GCR}} N\right)}$, the spatially weighted average over the oceans of the maximum response of supercritical aerosol concentrations to the increase of GCR ionization from solar maximum to minimum. Only locations were used for calculating these averages where supercritical aerosol concentrations exceeded the threshold of 0.001 particles per $\mathrm{cm}^{3}$. These locations cover between 63 and $64 \%$ of the Earth's surface.

\begin{tabular}{rrrrr}
\hline & $21 \mathrm{Mar}$ & $21 \mathrm{Jun}$ & $21 \mathrm{Sep}$ & $21 \mathrm{Dec}$ \\
\hline $300 \mathrm{hPa}$ & $1.9 \%$ & $-0.41 \%$ & $1.5 \%$ & $0.95 \%$ \\
$550 \mathrm{hPa}$ & $2.8 \%$ & $0.65 \%$ & $2.4 \%$ & $2.3 \%$ \\
$700 \mathrm{hPa}$ & $2.8 \%$ & $0.18 \%$ & $2.6 \%$ & $2.4 \%$ \\
$925 \mathrm{hPa}$ & $2.5 \%$ & $0.67 \%$ & $2.6 \%$ & $2.9 \%$ \\
\hline
\end{tabular}

ring near tops of marine boundary layer clouds and in regions of convective outflow. More recently, Ekman et al. (2006) investigated a convective cloud with a 3D cloud resolving model and showed that during the convective event, polluted air was transported from the boundary layer to the cloud top region, while aerosols were efficiently scavenged by cloud processes. The air in the cloud top region proved highly conducive to aerosol nucleation, even after dissipation of the cloud.

Our simulations show a negligible nucleation in the tropical MBL even in the absence of preexisting aerosol, and a weak nucleation in the tropical middle troposphere. In contrast, vigorous nucleation occurs in the upper troposphere, in particular above the ITCZ, where convection accounts for elevated $\mathrm{SO}_{2}$ concentrations (Fig. 1d), resulting in supercritical aerosol concentrations of up to $75000 \mathrm{~cm}^{-3}$ (Fig. 5d). This is consistent with observations by Brock et al. (1995), who found very high aerosol concentrations in the tropical upper troposphere, and much lower concentrations at midlatitudes. A similar distribution has also been presented by Clarke and Kapustin (2002), who show very high concentrations (up to $50000 \mathrm{~cm}^{-3}$ ) of ultrafine particles (between about 3 and $15 \mathrm{~nm}$ in diameter) occurring in the upper troposphere mainly over the ITCZ. Our results further the proposition that these particles in the tropical upper troposphere nucleate from convectively lifted and cloud processed boundary layer air, and represent the source of non-sea salt sulfate aerosol in the tropical MBL. However, while Brock et al. (1995) attributed the formation of these particles to neutral nucleation of $\mathrm{H}_{2} \mathrm{O}$ and $\mathrm{H}_{2} \mathrm{SO}_{4}$, charged nucleation dominates particle formation in our simulations. The uncertainties regarding the mechanism responsible for nucleation in the upper troposphere are discussed in Sect. 5.6.

\subsection{Effect of preexisting aerosol on aerosol nucleation}

The results presented in Sect. 4 were obtained assuming zero preexisting aerosol concentrations, which may lead to an overestimation of freshly nucleated particle concentrations. 
$\mathrm{N}_{3 n \mathrm{~m}}(24 \mathrm{~h})-\mathrm{N}_{3 n \mathrm{~m}}(\mathrm{Oh})\left(\mathrm{cm}^{-3}\right), 925 \mathrm{hPa}$

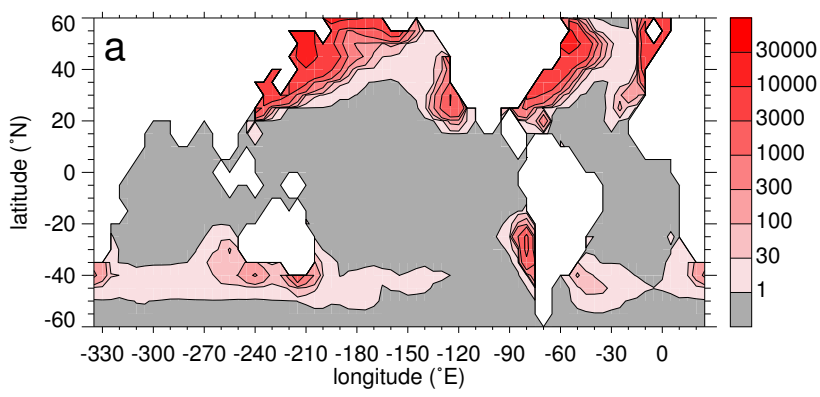

$\mathrm{N}_{3 n \mathrm{~m}}(24 \mathrm{~h})-\mathrm{N}_{3 \mathrm{~mm}}(0 \mathrm{~h})\left(\mathrm{cm}^{-3}\right), 550 \mathrm{hPa}$

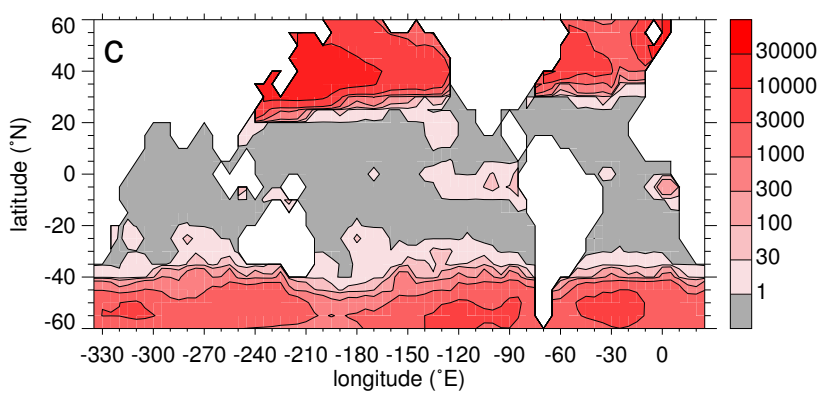

$\mathrm{N}_{3 n m}(24 \mathrm{~h})-\mathrm{N}_{3 n \mathrm{~m}}(\mathrm{hh})\left(\mathrm{cm}^{-3}\right), 700 \mathrm{hPa}$

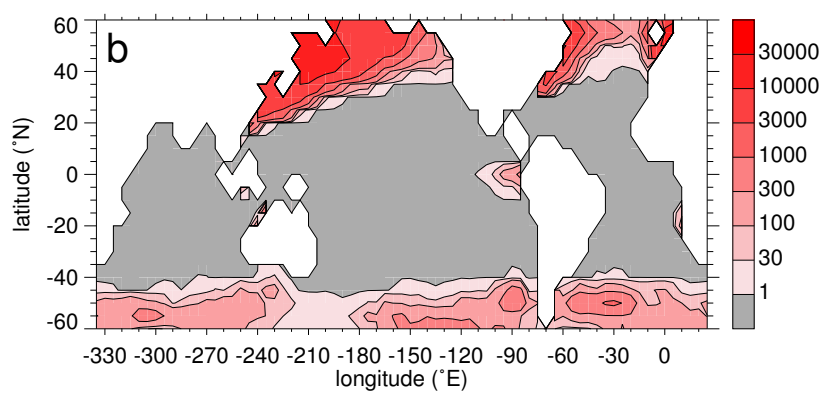

$\mathrm{N}_{3 \mathrm{~mm}}(24 \mathrm{~h})-\mathrm{N}_{3 \mathrm{~nm}}(0 \mathrm{~h})\left(\mathrm{cm}^{-3}\right), 300 \mathrm{hPa}$

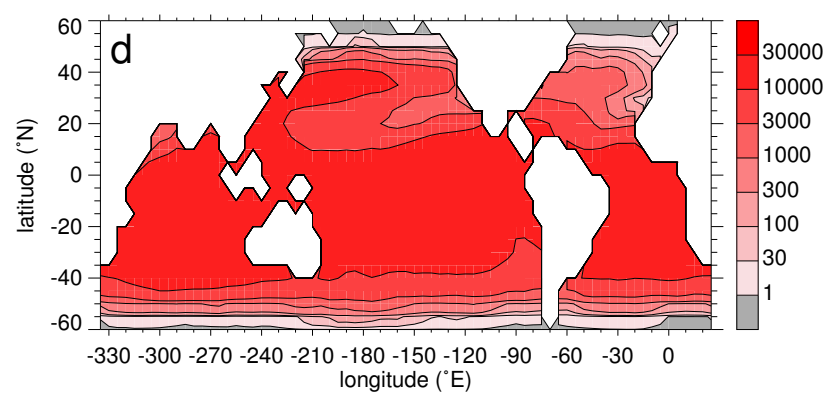

Fig. 9. Change of the $>3 \mathrm{~nm}$ diameter particle concentration from $0 \mathrm{~h}$ to $24 \mathrm{~h}, 21 \mathrm{March}$, calculated using solar maximum ionization rates, and with a preexisting surface area concentration of $2.5 \mu \mathrm{m}^{2} \mathrm{~cm}^{-3}$ at $0 \mathrm{~h}$. Pressure levels: $925 \mathrm{hPa}(\mathbf{a}), 700 \mathrm{hPa}(\mathbf{b}), 550 \mathrm{hPa}(\mathbf{c}), 300 \mathrm{hPa}(\mathbf{d})$.

This weighs most with regard to the high nucleation in the tropical upper troposphere, and least with regard to the marginal nucleation in the tropical MBL predicted by our model. However, it is based on this striking difference that we argue for the tropical upper troposphere as a source of non-sea salt sulfate aerosol in the tropical MBL. The question to answer is therefore "Can a vigorous nucleation be expected in the tropical upper troposphere in the presence of actual aerosol concentrations?" Specifying representative aerosol concentrations on global scales is not straightforward. A comprehensive survey of aerosol observations in the marine troposphere has been published by Clarke and Kapustin (2002). Their compilation shows that for both polluted and clean air, the aerosol surface area decreases with altitude: Lower tropospheric average surface area concentrations amount to approximately $45 \mu \mathrm{m}^{2} \mathrm{~cm}^{-3}$ in polluted and $10 \mu \mathrm{m}^{2} \mathrm{~cm}^{-3}$ in clean conditions. Above $7 \mathrm{~km}$, average surface area concentrations are less than $10 \mu \mathrm{m}^{2} \mathrm{~cm}^{-3}$ in both cases. These surface area concentrations are given at STP, hence the actual decrease of surface area concentration with altitude is steeper than these numbers indicate. The variability of individual measurements around the average values is substantial.

We have conducted a sensitivity study to investigate the effect of preexisting aerosol on nucleation, running our model with different preexisting aerosol surface area concentrations between 0 and $20 \mu \mathrm{m}^{2} \mathrm{~cm}^{-3}$ (in ambient temperature and pressure). The aerosol size distribution was initialized as a log-normal mode with a geometric mean diameter of $165 \mathrm{~nm}$ and with a geometric standard deviation as 1.45 based on values for marine accumulation mode aerosol given in the compilation of Heintzenberg et al. (2000). Here we will discuss the change of the $>3 \mathrm{~nm}$ diameter particle concentration from $0 \mathrm{~h}$ to $24 \mathrm{~h}$ of $21 \mathrm{March}$, calculated using solar maximum ionization rates: Comparing the concentrations of supercritical aerosol particles is not meaningful here, as the size of the neutral critical cluster depends on gas phase $\mathrm{H}_{2} \mathrm{SO}_{4}$ concentration, which again depends on the preexisting aerosol concentration, the parameter varied in the sensitivity study. Also, $3 \mathrm{~nm}$ is the smallest particle diameter that can be detected with current experimental techniques. Results for June, September and 21 December are qualitatively similar to those for 21 March.

At $2.5 \mu \mathrm{m}^{2} \mathrm{~cm}^{-3}$ preexisting aerosol surface area concentration, particle formation is suppressed in most of the tropical lower and middle troposphere (Figs. 9a, b, and c). High particle concentrations emerge in the mid-latitudes of the lower and middle troposphere, but most notably in the upper troposphere (Fig. 9 d). At $10 \mu \mathrm{m}^{2} \mathrm{~cm}^{-3}$, the production of $>3 \mathrm{~nm}$ diameter particles in the lower and middle troposphere is reduced to pockets around coastal areas (Figs. 10a-c). At the same time, the upper troposphere 
$\mathrm{N}_{3 n \mathrm{~m}}(24 \mathrm{~h})-\mathrm{N}_{3 n \mathrm{~m}}(\mathrm{Oh})\left(\mathrm{cm}^{-3}\right), 925 \mathrm{hPa}$

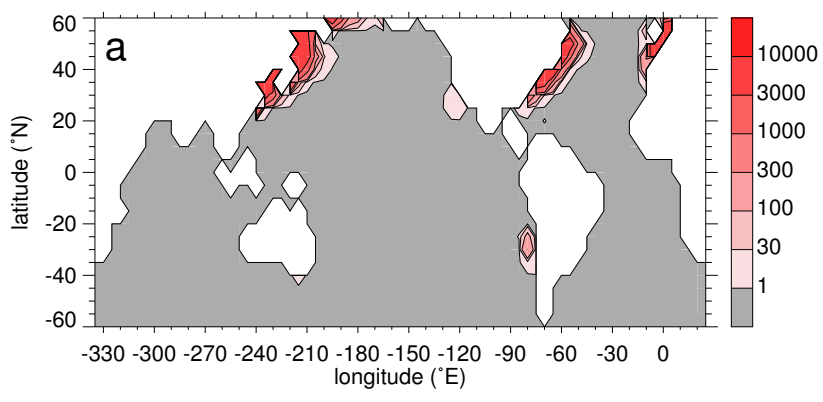

$\mathrm{N}_{3 \mathrm{~nm}}(24 \mathrm{~h})-\mathrm{N}_{3 \mathrm{~nm}}(0 \mathrm{~h})\left(\mathrm{cm}^{-3}\right), 550 \mathrm{hPa}$

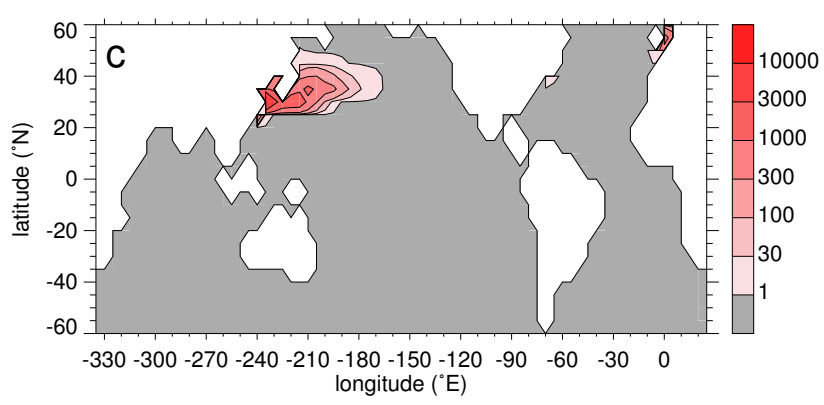

$\mathrm{N}_{3 n \mathrm{~m}}(24 \mathrm{~h})-\mathrm{N}_{3 \mathrm{~nm}}(0 \mathrm{~h})\left(\mathrm{cm}^{-3}\right), 700 \mathrm{hPa}$

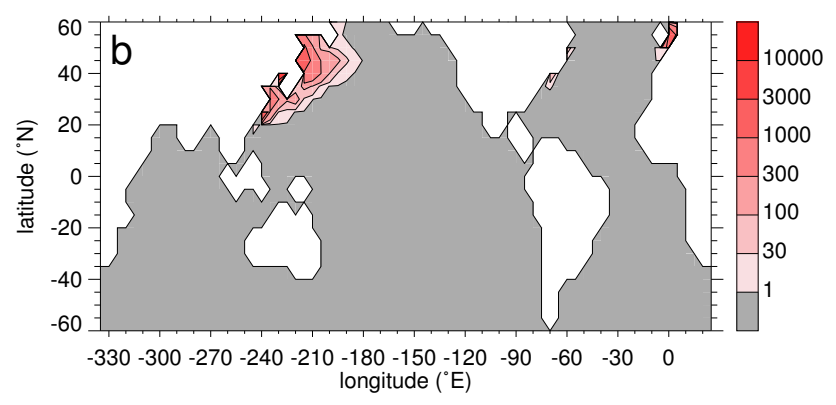

$\mathrm{N}_{3 \mathrm{~mm}}(24 \mathrm{~h})-\mathrm{N}_{3 \mathrm{~nm}}(\mathrm{Oh})\left(\mathrm{cm}^{-3}\right), 300 \mathrm{hPa}$

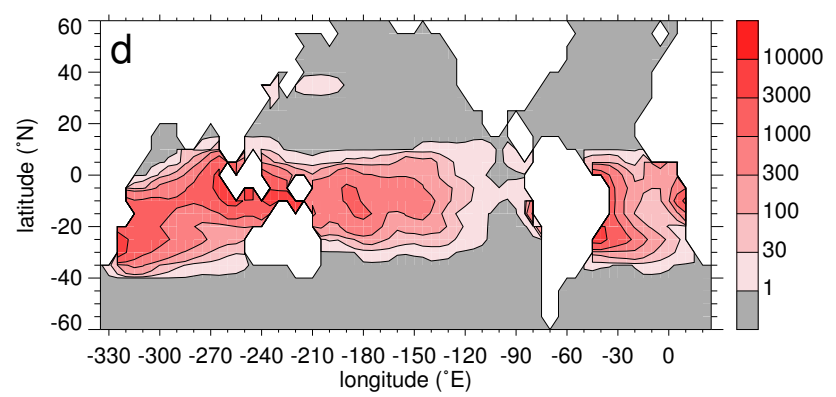

Fig. 10. Change of the $>3 \mathrm{~nm}$ diameter particle concentration from $0 \mathrm{~h}$ to $24 \mathrm{~h}, 21$ March, calculated using solar maximum ionization rates, and with a preexisting surface area concentration of $10 \mu \mathrm{m}^{2} \mathrm{~cm}^{-3}$ at $0 \mathrm{~h}$. Pressure levels: $925 \mathrm{hPa}$ (a), $700 \mathrm{hPa}(\mathbf{b}), 550 \mathrm{hPa}(\mathbf{c}), 300 \mathrm{hPa}(\mathbf{d})$.

$$
\mathrm{N}_{3 n \mathrm{~m}}(24 \mathrm{~h})-\mathrm{N}_{3 \mathrm{~nm}}(0 \mathrm{~h})\left(\mathrm{cm}^{-3}\right), 300 \mathrm{hPa}
$$

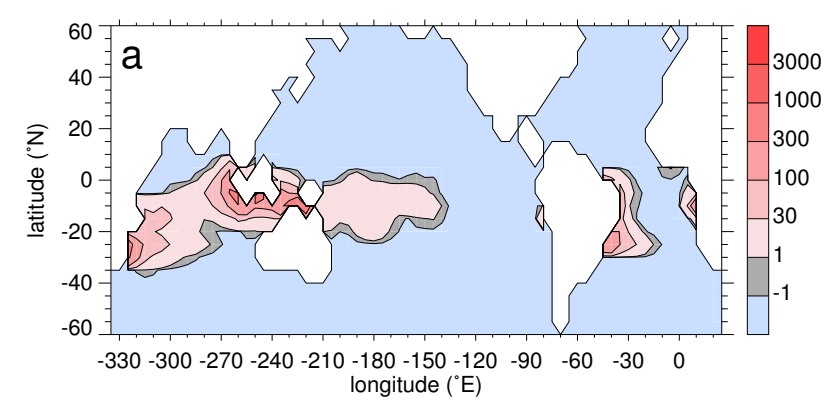

$\mathrm{N}_{3 \mathrm{~nm}}(24 \mathrm{~h})-\mathrm{N}_{3 \mathrm{~nm}}(0 \mathrm{~h})\left(\mathrm{cm}^{-3}\right), 300 \mathrm{hPa}$

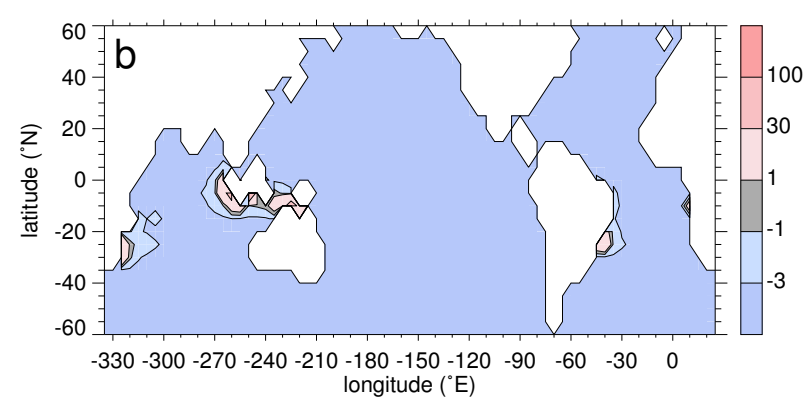

Fig. 11. Change of the $>3 \mathrm{~nm}$ diameter particle concentration from $0 \mathrm{~h}$ to $24 \mathrm{~h}, 21$ March, calculated using solar maximum ionization rates, with a preexisting surface area concentration of $15 \mu \mathrm{m}^{2} \mathrm{~cm}^{-3}$ (a) and $20 \mu \mathrm{m}^{2} \mathrm{~cm}^{-3}$ (b) at $0 \mathrm{~h}$, at $300 \mathrm{hPa}$. The decrease of aerosol concentrations in areas where no new aerosol has formed is due to coagulation of the preexisting aerosol particles.

is capable of a widespread $>3 \mathrm{~nm}$ diameter particle production (Fig. 10d). At $15 \mu \mathrm{m}^{2} \mathrm{~cm}^{-3}$, particle production is still proceeding in the upper troposphere over the western Pacific warm pool, where deep convection is most frequent, and downwind of convection occurring in south America (Fig. 11a), but has mostly disappeared at $20 \mu \mathrm{m}^{2} \mathrm{~cm}^{-3}$ (Fig. 11b).
The question posed above can be answered in the affirmative: Indeed, a vigorous nucleation can be expected in the tropical upper troposphere in the presence of actual aerosol concentrations. More specifically, in the adopted average conditions and for the nucleation mechanisms accounted for in our model, the tropical upper troposphere can maintain particle formation at preexisting aerosol surface area concentrations above observed average values, while the middle and 
lower tropical troposphere require a reduction of aerosol surface area concentrations below observed average values, or favorable deviations from average $\mathrm{SO}_{2}$ concentrations, temperatures, relative humidities, or the contribution of ammonia or other aerosol precursor gases to produce particles. This result supports our finding on the role of nucleation related to convective lifting of boundary layer air into the upper troposphere over the oceans as a source of MBL aerosols.

\subsection{Sources of stratospheric condensation nuclei}

Brock et al. (1995) showed that a source of condensation nuclei in the tropical upper troposphere can explain observed stratospheric aerosol concentrations in the absence of volcanic activity if transport of the condensation nuclei from the tropical upper troposphere by the residual stratospheric circulation and their coagulation are taken into account. No stratospheric particle source is required. In the light of our simulations and the observations of ultrafine particles in the outflow of convective clouds (Clarke, 1993; Clarke et al., 1998b, 1999; Wang et al., 2000; Twohy et al., 2002; Clarke and Kapustin, 2002) this source appears to be driven by convective lifting of aerosol precursor gases from the marine boundary layer. However, convection as a mechanism responsible for the formation of stratospheric condensation nuclei needs not to be restricted to the tropics, as Fischer et al. (2003) have observed injection of boundary layer air into the stratosphere by deep convection at mid-latitudes.

\subsection{Sea surface temperatures and aerosol nucleation}

Convection and cloud processing of boundary layer air as a mechanism initiating nucleation in the tropical upper troposphere, maintaining the tropical marine boundary layer aerosol concentrations, and supplying condensation nuclei to the stratosphere has interesting, but speculative implications: Convection and the associated cloud processes depend on sea surface temperatures, which are controlled by internal processes of the climate system, and by anthropogenic and solar forcing (Reid, 1987; White et al., 1997, 1998). Hence sea surface temperatures and its controlling factors potentially influence particle formation in the upper troposphere, and ultimately marine boundary layer and stratospheric aerosol concentrations, with subsequent effects on radiative transfer, atmospheric chemistry, and meteorology.

\subsection{Galactic cosmic rays, aerosols, and clouds}

Numerous studies have discussed an apparent correlation of cloud cover and GCR intensity: At solar minimum, when GCR intensity peaks, the global cloud cover would be larger compared with solar maximum, when GCR intensity dips. The correlation was first reported by Svensmark and Friis-Christensen (1997), who found a 3-4\% variation of the global cloud cover over a solar cycle based on data of the International Satellite Cloud Climatology Project
(ISCCP) (Rossow and Schiffer, 1991) for the years 19831992. Kristjánsson and Kristiansen (2000) pointed out that the correlation may be purely coincidental, as the ISCCP data showed a divergence of cloud cover and GCR intensity in the years 1991-1994, but concluded that global cloud fraction is higher by 0.0176 and radiative forcing reduced by $0.29 \mathrm{~W} \mathrm{~m}^{-2}$ at solar minimum 1986 compared with solar maximum 1990. Marsh and Svensmark (2000) confined the correlation to clouds over land and ocean below $680 \mathrm{hPa}$ for the period 1983-1994. They estimated that global low cloud fraction is higher at solar minimum by 0.02 and radiative forcing reduced by $1.2 \mathrm{~W} \mathrm{~m}^{-2}$ compared with solar maximum. Kristjánsson et al. $(2002,2004)$ analyzed the revised ISCCP cloud dataset (Rossow and Schiffer, 1999) for the period 1983-2001 and found a weak correlation between low cloud cover and GCR intensity, and a much better correlation between low cloud cover and total solar irradiance. They proposed a mechanism connecting solar irradiance and low clouds, rather than GCR and low clouds.

A mechanism linking galactic cosmic rays, aerosols and clouds has been outlined initially by Dickinson (1975): Sulfate aerosol particles forming from ions produced by GCR might grow to cloud condensation nuclei (CCN) and eventually become cloud droplets. The variation of GCR ionization over the solar cycle would thus appear in cloud droplet concentrations and hence in cloud albedo via the first indirect aerosol effect (Twomey, 1977) and cloud lifetime via the second indirect aerosol effect (Albrecht, 1989). The result would be a solar cycle modulation of radiative forcing of the troposphere.

We can estimate the response of cloud properties to a change in aerosol concentrations via the first and second indirect effects and the associated change in radiative forcing: Sekiguchi et al. (2003) derived the expressions

$n_{2}-n_{1}=\log _{10}\left(\frac{\hat{N}_{2}}{\hat{N}_{1}}\right)^{0.0857 \pm 0.0253}$

and

$\frac{\tau_{2}}{\tau_{1}}=\left(\frac{\hat{N}_{2}}{\hat{N}_{1}}\right)^{0.156 \pm 0.046}$

relating differences in aerosol column concentrations $\hat{N}$ to differences in cloud fraction $n$ and cloud optical thickness $\tau$ from aerosol and cloud parameters obtained from the Advanced Very High Resolution Radiometer (AVHRR) (Kidwell, 1998) and from the Polarization and Directionality of the Earth's Reflectance (POLDER) (Deschamps et al., 1994) satellite instruments.

Cloud albedo $A_{c}$ can be calculated from cloud optical thickness with

$A_{c}=\frac{(1-g) \tau}{2+(1-g) \tau}$ 
(Bohren, 1987), with the scattering asymmetry factor $g \approx 0.85$. The daily mean shortwave radiative forcing $Q_{S W}$ over an ocean location can then be approximated with

$$
\begin{gathered}
Q_{S W} \approx S\left[1-\left(n A_{c}+(1-n) A_{S}\right) T^{2}\right] \\
\cdot \frac{\int_{\text {sunrise }}^{\text {sunset }} d t \cos (\operatorname{SZA}(t))}{\int_{0 \mathrm{~h}}^{24 \mathrm{~h}} d t}
\end{gathered}
$$

with the total radiative output from the Sun at the Earth $S=1366 \mathrm{~W} \mathrm{~m}^{-2}$ (Lean and Rind, 1998), the ocean surface albedo $A_{S}$, and the atmospheric transmission $T$. Setting $T=1$ maximizes the response of $Q_{S W}$ to a change in cloud properties. We adopt a mean cloud fraction $n=0.34$ of stratiform clouds over the oceans (Warren et al., 1986), the average optical depth $\tau=5.26$ of low level clouds over the oceans (Kawamoto et al., 2001), and a mean ocean surface albedo $A_{s}=0.06$ (Satheesh et al., 2002).

Equation (2) shows that an increase in aerosol column concentration by $71 \%$ would be required to increase cloud fraction by 0.02 . However, over our model area, the maximum increase in ionization rate from solar maximum to minimum amounts to $13.0 \%, 17.5 \%, 21.5 \%$, and $27.6 \%$ at the 925,700 , 550 , and $300 \mathrm{hPa}$ pressure levels, respectively. The correlations of Sekiguchi et al. (2003) therefore imply that the increase in cloud fraction from solar maximum to minimum reported by Marsh and Svensmark (2000) for the ISCCP dataset is unlikely due to ions growing to aerosol particles. Nonetheless, by applying Eqs. (2)-(5) to our model results we can obtain an estimate of the upper limit to the response of cloud fraction $\delta n$, cloud albedo $\delta A_{c}$, and shortwave radiative forcing $\delta Q_{S W}$ to the change in GCR ionization over the solar cycle. For this purpose we assume that the maximum effect occurs when the aerosol particles visible to satellites carry the same response to a change in ionization as the small, recently nucleated supercritical particles, or equivalently, that each of the aerosol particles visible to satellites evolved from one of the recently nucleated supercritical aerosol particles. However, our model does not give aerosol column concentrations, but only aerosol concentrations at selected pressure levels. We will therefore perform the calculations assuming that aerosol that nucleated at either the 925 or the $700 \mathrm{hPa}$ pressure levels dominates the aerosol column concentration. With these two pressure levels we cover the lower troposphere, where clouds with most impact on the shortwave forcing and the apparent GCR-cloud correlation are located. We will show that the choice of pressure level for the origin of the aerosol has little impact on the results.

Figure 12 shows the spatial distribution of $\max \left(\Delta_{\mathrm{GCR}} N\right)$ for $21 \mathrm{March}$ at $925 \mathrm{hPa}$ (a) and at $700 \mathrm{hPa}$ (b). The corresponding change of cloud fraction $\delta n$ is shown in Figs. 12c, $\mathrm{d}$, and the change in cloud albedo $\delta A_{c}$ in Fig. 12e, f. Figures $12 \mathrm{~g}$, h show the associated change in daily mean shortwave radiative forcing $\delta Q_{S W}$. A notable feature of these distributions is the strong response of cloud properties and radiative forcing in regions with elevated $\mathrm{SO}_{2}$ concentrations (see Figs. 1a, b), in particular in the northern hemisphere, where anthropogenic $\mathrm{SO}_{2}$ is prevalent. This permits the conclusion that in these regions we would have obtained a lesser response of cloud properties and of radiative forcing to the variation in GCR intensity over the solar cycle using pre-industrial $\mathrm{SO}_{2}$ concentrations, except during periods of volcanic activity. The spatially weighted averages of the quantities shown in Fig. 12 are given in Table 3. Except for June, when the annual $\mathrm{SO}_{2}$ cycle has a minimum and the large southern oceans receive comparably little sunlight, the averaged quantities assume similar values, independent of the pressure level. In all cases, the change in daily mean shortwave radiative forcing from solar maximum to minimum falls short of the concurrent decrease of $0.1 \%$ in total solar irradiance from solar maximum to minimum (Lean and Rind, 1998), which amounts to $-0.24 \mathrm{~W} \mathrm{~m}^{-2}$.

It is important to point out that at each step of our derivation of the effects of GCR intensity variations on aerosol concentrations, cloud properties, and on radiative forcing we aimed at obtaining an upper limit: We chose the most favorable conditions for a positive response of aerosol nucleation to the change in GCR ionization from solar maximum to minimum, and then picked at every location of the model area the largest response in the course of the day. In addition, we used the response of supercritical aerosol concentration, which exhibits a larger response to GCR ionization than the concentration of larger particles, which will become CCN first. We neglected that cloud droplets may form from aerosol that does not originate from ions, which would reduce the response of cloud properties to GCR ionization. We neglected atmospheric absorption and calculated the change in shortwave radiative forcing, which overestimates the net change in radiative forcing, as an increase in cloud cover reduces infrared cooling of the surface. We also calculated the change in shortwave radiative forcing for oceanic regions, which is greater than the shortwave radiative forcing for continental regions due to the lower surface albedo and the higher stratiform cloud fraction over the oceans.

\subsection{Uncertainties}

This work represents only a step towards an accurate description of the phenomena it addresses, and is subject to a number of uncertainties:

- Aerosol nucleation often depends non-linearly on composition and ambient conditions (Andronache et al., 1997). Calculations based on instantaneous mixing ratios and state parameters rather than the mean values used in this study may yield higher average nucleation rates in the lower troposphere and increase the sensitivity of the aerosol population to GCR ionization during the course of the solar cycle. An analysis of the diurnal variation of upper air temperature (Seidel et al., 2005) 


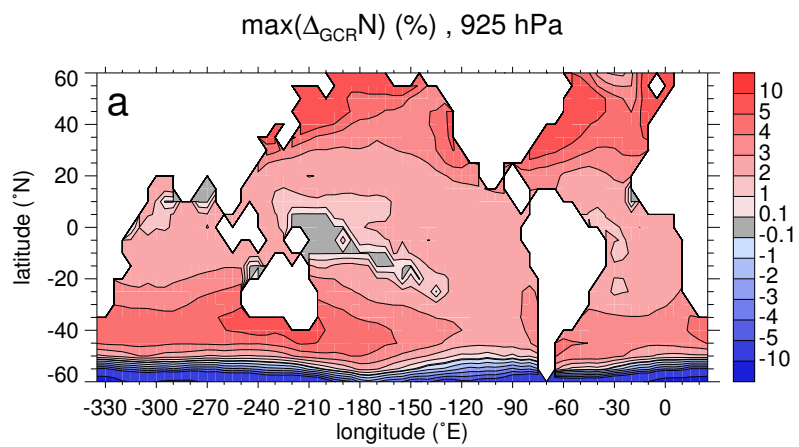

$\delta \mathrm{n}, 925 \mathrm{hPa}$

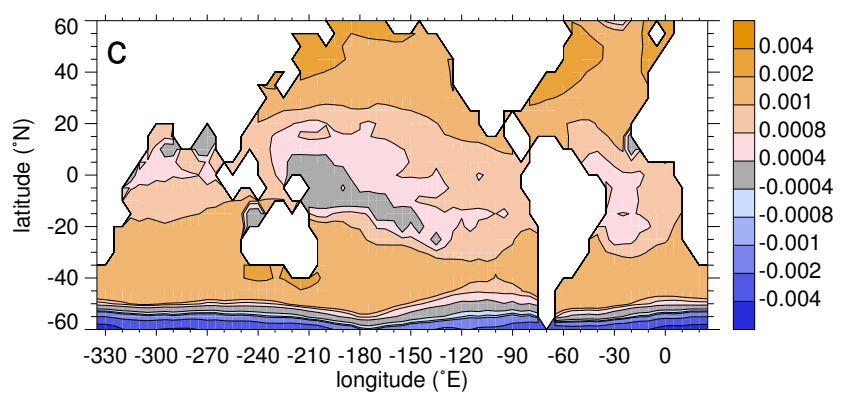

$\delta \mathrm{A}_{\mathrm{c}}, 925 \mathrm{hPa}$

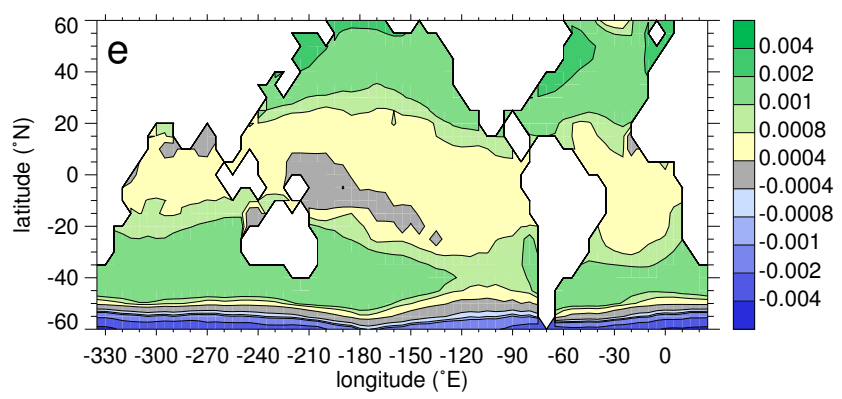

$\delta Q_{\mathrm{sW}}\left(\mathrm{W} \mathrm{m} \mathrm{m}^{-2}\right), 925 \mathrm{hPa}$

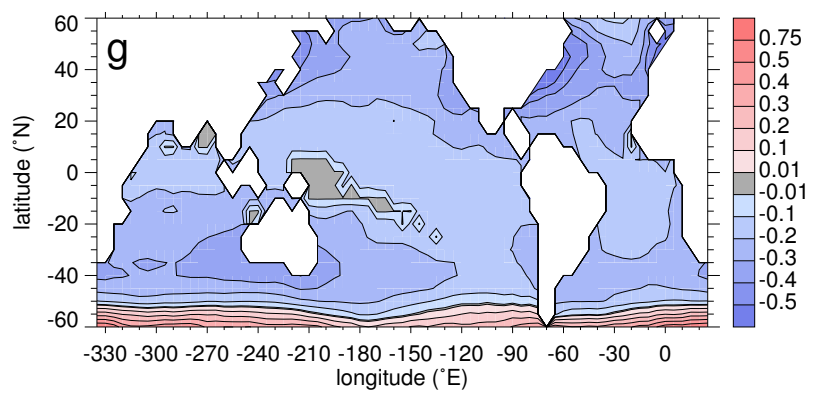

$\max \left(\Delta_{\mathrm{GCR}} \mathrm{N}\right)(\%), 700 \mathrm{hPa}$

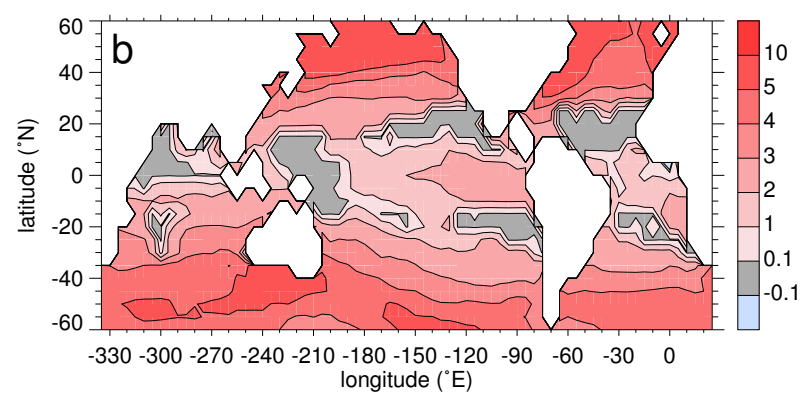

$\delta \mathrm{n}, 700 \mathrm{hPa}$

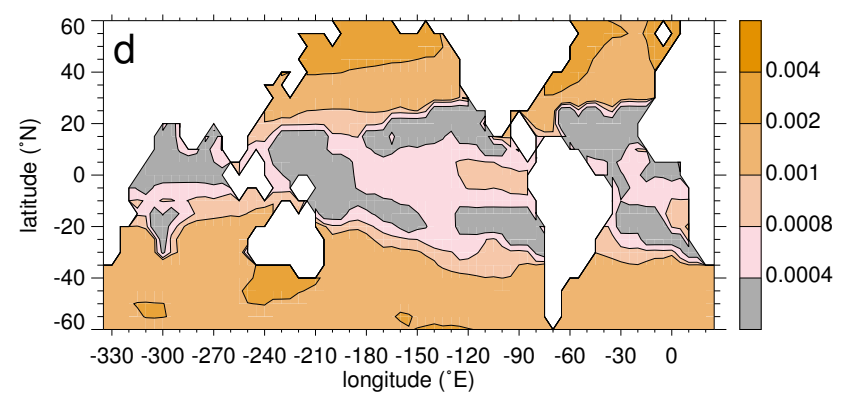

$\delta \mathrm{A}_{\mathrm{c}}, 700 \mathrm{hPa}$

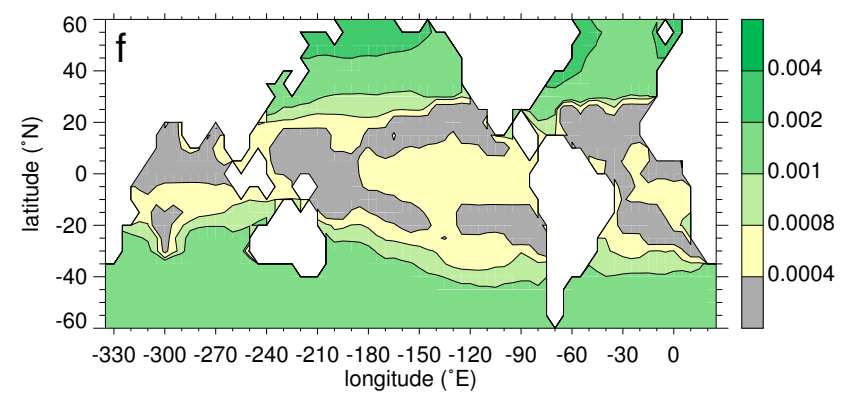

$\delta Q_{\mathrm{SW}}\left(\mathrm{W} \mathrm{m} \mathrm{m}^{-2}\right), 700 \mathrm{hPa}$

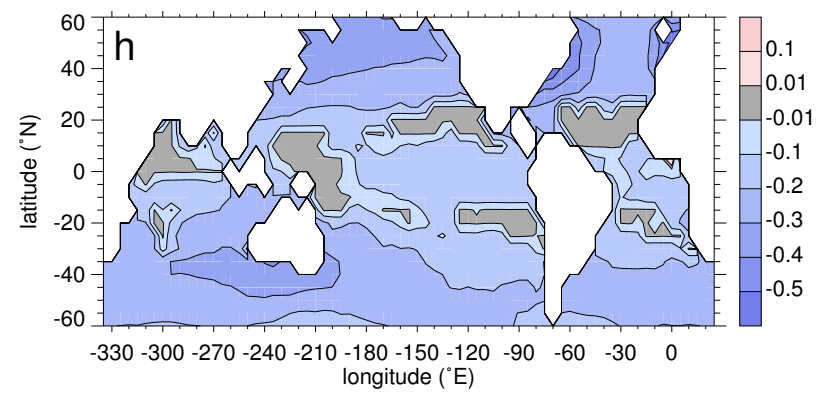

Fig. 12. Spatial distributions of $\max \left(\Delta_{\mathrm{GCR}} N\right)(\mathbf{a}, \mathbf{b})$, and of the resulting change in cloud fraction $\delta n(\mathbf{c}, \mathbf{d})$, cloud albedo $\delta A(\mathbf{e}, \mathbf{f})$, and in the daily mean shortwave radiative forcing $\delta Q_{S W}(\mathbf{g}, \mathbf{h})$ for aerosol that nucleated at the $925 \mathrm{hPa}$ (left) and $700 \mathrm{hPa}$ (right) levels, on $21 \mathrm{March}$. 
Table 3. Spatially weighted average of $\max \left(\Delta_{\mathrm{GCR}} N\right)$, and of the resulting difference in cloud fraction $\delta n$, cloud albedo $\delta A_{c}$, and of the daily mean shortwave radiative forcing $\delta Q_{S W}$ between solar maximum and minimum over the oceans, assuming the aerosol column concentration is dominated by aerosol that nucleated at the indicated pressure level. Only model grid locations were included in these averages if the supercritical aerosol concentrations exceeded the threshold of 0.001 particles per $\mathrm{cm}^{3}$. These locations cover between 63 and $64 \%$ of the Earth's surface.

\begin{tabular}{llllll}
\hline & & $21 \mathrm{Mar}$ & $21 \mathrm{Jun}$ & $21 \mathrm{Sep}$ & $21 \mathrm{Dec}$ \\
\hline \multirow{2}{*}{$700 \mathrm{hPa}$} & $\overline{\max \left(\Delta_{\mathrm{GCR}} N\right)}$ & $2.8 \%$ & $0.18 \%$ & $2.6 \%$ & $2.4 \%$ \\
& $\overline{\delta n}$ & 0.0011 & 0.000047 & 0.00098 & 0.00093 \\
& $\overline{\delta A_{c}}$ & 0.0009 & 0.00004 & 0.00084 & 0.00079 \\
& $\overline{\delta Q_{S W}}$ & $-0.18 \mathrm{~W} \mathrm{~m}^{-2}$ & $-0.11 \mathrm{~W} \mathrm{~m}^{-2}$ & $-0.17 \mathrm{~W} \mathrm{~m}^{-2}$ & $-0.19 \mathrm{~W} \mathrm{~m}^{-2}$ \\
& & & & & \\
$925 \mathrm{hPa}$ & $\overline{\max \left(\Delta_{\mathrm{GCR}} N\right)}$ & $2.5 \%$ & $0.67 \%$ & $2.6 \%$ & $2.9 \%$ \\
& $\overline{\delta n}$ & 0.00094 & 0.00023 & 0.00097 & 0.0011 \\
& $\overline{\delta A_{c}}$ & 0.0008 & 0.00019 & 0.00083 & 0.00094 \\
& $\overline{\delta Q_{S W}}$ & $-0.18 \mathrm{~W} \mathrm{~m}^{-2}$ & $-0.14 \mathrm{~W} \mathrm{~m}^{-2}$ & $-0.19 \mathrm{~W} \mathrm{~m}^{-2}$ & $-0.22 \mathrm{~W} \mathrm{~m}^{-2}$ \\
\hline
\end{tabular}

shows that the range of the diurnal upper air temperature variation remains generally below about $2 \mathrm{~K}$ over the oceans. A diurnal temperature variation would not change our conclusions, however, as during the day, when new particles form in our model, it would entail temperatures higher than the average used in our simulations. Variability on shorter timescales, such as resulting from cold/warm front passages may exceed the diurnal temperature range and be more relevant for new particle formation. However, variations in composition and ambient conditions would not result in a higher contribution of neutral binary nucleation to particle formation compared with charged binary nucleation in our simulations: Temperature, relative humidity, $\mathrm{SO}_{2}$ and $\mathrm{OH}$ concentrations vary more strongly over our model area than can be expected for one given location, with neutral nucleation remaining negligible everywhere.

- Input data errors: Temperature, relative humidity, and the $\mathrm{SO}_{2}$ and $\mathrm{OH}$ concentrations used in our simulations may differ from the actual climatological means, as the models used for their calculation resolve only selected processes above a certain spatial scale, while sub-grid processes are parameterized. A parameterization of convection overestimating e.g. the transport of $\mathrm{SO}_{2}$ from the lower to the upper troposphere would thwart nucleation in the former and favor it in the latter. This would lead to an underestimation of the aerosol response in the lower troposphere to the variation in GCR ionization over the solar cycle. At the same time, the upper troposphere would appear as a more powerful source of new particles compared with the lower troposphere.
- Binary nucleation: The thermodynamic data for the small charged $\mathrm{H}_{2} \mathrm{SO}_{4} / \mathrm{H}_{2} \mathrm{O}$ clusters used in our model have been determined in the laboratory. In contrast, the thermodynamic data for the small neutral clusters are based on theoretical considerations, and have been adjusted to reproduce experimental nucleation rates. Therefore, while the majority of the particles in our simulations originates from charged nucleation, we cannot rule out efficient neutral binary nucleation, e.g. in the upper troposphere (at the $300 \mathrm{hPa}$ level and above), where temperatures are low. The charged nucleation rate, however, is subject to uncertainties in the neutral thermodynamic data as well: $\mathrm{The}_{2} \mathrm{SO}_{4}$ content of the neutral critical cluster, which is a function of temperature and $\mathrm{H}_{2} \mathrm{SO}_{4}$ concentration, influences the strength of nucleation from the charged channel.

- Ternary nucleation: While neutral ternary nucleation at ammonia concentrations as low as 5 ppt is predicted by model studies (Pirjola et al., 2000; Kulmala et al., 2002), a recent experimentally constrained kinetic model of neutral ternary nucleation (Yu, 2005) indicates a negligible contribution of this mechanism to new particle formation in the tropospheric boundary layer. Observations show that in clean marine areas such as in the tropical Pacific, nucleation needs not to proceed even at very high $\mathrm{H}_{2} \mathrm{SO}_{4}$ concentrations (Weber et al., 2001b). Moreover, Brock et al. (1995) analyzed upper tropospheric aerosol and concluded that its composition is consistent with $\mathrm{H}_{2} \mathrm{O}$ and $\mathrm{H}_{2} \mathrm{SO}_{4}$ only in tropical regions, while additionally containing a non-volatile component, possibly ammonium, at extra-tropical locations. Similarly, Yamato and Tanaka (1994) found that in the unpolluted free marine troposphere, sulfuric acid aerosol particles are neutralized by ammonia at 
a small degree, while in marine air masses originating from land, ammoniated particles dominate over sulfuric acid particles. These examples illustrate that ternary neutral nucleation involving ammonia is not necessarily involved in new particle formation in the unpolluted marine troposphere. Nonetheless, efficient neutral ternary nucleation cannot be ruled out, in particular over and near the continents, where ammonia concentrations are elevated (Dentener and Crutzen, 1994). Then a variation of radiative forcing and cloud properties due to aerosol production responding to the change of GCR ionization in the course of the solar cycle could not be expected in these regions. In the case of efficient neutral ternary nucleation throughout the MBL, changes in ionization would have no effect on aerosol production, and upper tropospheric nucleation as a mechanism maintaining the MBL aerosol population would not be required. On the other hand, particle formation from charged ternary nucleation cannot be excluded, e.g. at locations with suitable ammonia concentrations, which would accelerate the formation of supercritical clusters from ions and thus increase a response of aerosol concentrations to the variation in GCR ionization.

- Positive ion chemistry: Cations are represented summarily by $\mathrm{H}_{3} \mathrm{O}^{+}\left(\mathrm{H}_{2} \mathrm{O}\right)_{4}$ in our model. Heavier cations which recombine less rapidly with anions could allow more negative sulfuric acid/water clusters to grow to supercritical sizes before being neutralized. Complex cations, containing compounds other than water, could contribute to nucleation by recombination (Turco et al., 1998). This possibility is supported by the observations of Eichkorn et al. (2002), who observed massive positive ions in the upper troposphere. Positive sulfuric acid/water clusters e.g., while less potent to promote aerosol nucleation compared with their negative counterparts at temperatures of the lower troposphere (Froyd and Lovejoy, 2003a), might therefore enhance production of neutral supercritical sulfate aerosol from recombination in favorable conditions such as in the upper troposphere, where temperatures are low.

- Cloud-aerosol interactions: Ultrafine aerosol particles are removed efficiently by precipitation (Andronache, 2004) before growing to cloud condensation nuclei. However, an increase in aerosol concentrations reduces drizzle via the second indirect aerosol effect and thus the removal of ultrafine particles. Conversely, a reduction of aerosol concentrations increases drizzle and the removal of ultrafine particles. Hence in regions where aerosol nucleation is correlated with ionization, the removal of ultrafine particles by precipitation would be reduced (enhanced) at times of increased (reduced) ionization. This feedback mechanism could result in a higher aerosol response to the variation in GCR ionization over the solar cycle in the lower troposphere than predicted by our model. On the other hand, recent observations (Twohy et al., 2005) showed that while differences in aerosol concentrations did affect cloud droplet concentrations, cloud droplet sizes, and drizzle rates in accordance with the first (Twomey, 1977) and second (Albrecht, 1989) indirect aerosol effects, the cloud optical depth and albedo remained unaffected, possibly due to concurrent changes in cloud thickness and liquid water path. This would imply a reduced response of cloud radiative forcing to a variation of aerosol concentrations resulting from changes in GCR ionization in the course of the solar cycle.

- Transport: Aerosol particles that are advected from strong localized sources and distributed over extended regions where they are activated to cloud droplets may strengthen (weaken) the response of cloud radiative forcing to a change in ionization depending on whether charged (neutral) nucleation prevails in the source region.

- Interpretation of satellite observations: The causal relationship between aerosol column concentrations and cloud properties implied by the correlations of Sekiguchi et al. (2003) is not mandatory: E.g., as discussed in Sect. 5.1, production of aerosol particles by clouds might contribute to the observed aerosol column concentration, thus weakening the causality. Also, satellite observations deliver clear-sky aerosol concentrations (Higurashi and Nakajima, 1999; Higurashi et al., 2000), while cloud properties may be determined by below cloud aerosol (Twohy et al., 2005), which is inaccessible to satellite observations.

We will try to assess here the uncertainty in our conclusions caused by neglecting the variability of composition and ambient conditions around the average values used in our simulations, and due to possible errors in these averages by means of a sensitivity study: Let us consider aerosol nucleation in the absence of preexisting aerosol, at 10 times the $\mathrm{SO}_{2}$ concentration of our original simulations, in a relative humidity of $100 \%$, and at temperatures $5 \mathrm{~K}$ below the long term daily mean. Our model predicts considerably higher aerosol concentrations in these conditions in the lower and middle troposphere (at the 925, 700, and 550 hPa pressure levels), which, however, remain below the noon aerosol concentrations at the $300 \mathrm{hPa}$ level (Fig. 1d) in the original conditions at all times. A change of shortwave radiative forcing from solar maximum to minimum due to the response of cloud cover and albedo to the change in aerosol nucleation of at most $0.44 \mathrm{~W} \mathrm{~m}^{-2}$ results from the modified conditions in the lower troposphere, twice as high as the maximum determined in the original conditions (Table 3). Consequently, our conclusions would be significantly different only if the majority of marine boundary layer aerosol nucleated in the modified or more favorable conditions. Such conditions might occur e.g after the 
passage of a cold front, in the course of which frontal precipitation has cleaned the air from preexisting aerosol particles. However, $\mathrm{SO}_{2}$ concentrations elevated well above the average would have to coincide with cold fronts. This sensitivity study also shows what results might be expected if all MBL aerosol formed from neutral and charged binary nucleation at temperatures reduced by $5 \mathrm{~K}$ below the average, in the immediate vicinity of stratiform clouds such as observed by Hegg et al. (1990), where relative humidity can approach $100 \%$, and with $\mathrm{SO}_{2}$ elevated e.g. due to advection of near-surface air containing DMS and $\mathrm{SO}_{2}$ by large eddies.

\section{Conclusions}

Our results support the proposition that non-sea salt sulfate aerosol does not form in the tropical marine boundary layer, but in the upper troposphere, where it nucleates from convectively lifted and cloud processed boundary layer air rich in aerosol precursor gases. The newly formed particles slowly descend and grow in subsiding air masses compensating convection, and eventually enter the marine boundary layer, replenishing its aerosol population. At the same time, our results indicate that convection of marine boundary layer air supplies aerosol precursor gases to the source of condensation nuclei in the tropical upper troposphere which maintains the stratospheric aerosol layer in the absence of volcanic activity. While charged binary nucleation accounts for most of the aerosol production in our simulations, we cannot exclude that neutral binary nucleation of water and sulfuric acid or neutral and charged ternary nucleation of water, sulfuric acid, and ammonia do take place in the marine troposphere. Nonetheless, observations show that in clean marine regions, ammonia is not necessarily involved in new particle formation, making contributions from ions likely. However, our results indicate that the change in ionization by galactic cosmic rays in the course of the decadal solar cycle does not entail a response in aerosol production and cloud cover via the second indirect aerosol effect that would explain observed variations in global cloud cover. We estimate that the change in radiative forcing resulting from a response of clouds via first and second indirect aerosol effect to the increase in galactic cosmic ray ionization and subsequent aerosol production from solar maximum to minimum is at most $-0.22 \mathrm{~W} \mathrm{~m}^{-2}$ in industrial times, less than the concurrent variation of total solar irradiance, and expect a smaller effect in pre-industrial times, except during periods of volcanic activity.

Acknowledgements. We thank C. Spivakovsky (Harvard University) for providing the $\mathrm{OH}$ concentrations used in this work, U. Lohmann (ETH Zurich), G. Feingold and K. Froyd (NOAA Earth System Research Laboratory), and F. Eisele (NCAR Atmospheric Chemistry Division) for helpful discussions, and three anonymous reviewers for their constructive comments. The first author gratefully acknowledges W. A. Cooper, the NCAR Advanced Study Program, and the NCAR High Altitude Observatory for their kind support. The majority of this work was carried out within and funded by the NCAR Advanced Study Program and supported in part by the NOAA Climate and Global Change Program. The National Center for Atmospheric Research is sponsored by the National Science Foundation.

Edited by: M. Kulmala

\section{References}

Albrecht, B. A.: Aerosols, cloud microphysics and fractional cloudiness, Science, 245, 1227-1230, 1989.

Allkofer, O. C. and Grieder, P. F. K.: Cosmic Rays on Earth, Physics Data Series, vol. 25-1, Fachinformationszentrum Karlsruhe, 1984.

Andronache, C.: Precipitation removal of ultrafine aerosol particles from the atmospheric boundary layer, J. Geophys. Res., 109, D16S07, doi:10.1029/2003JD004050, 2004.

Andronache, C., Chameides, W. L., Davis, D. D., Anderson, B. E., Pueschel, R. F., Bandy, A. R., Thornton, D. C., Talbot, R. W., Kasibhatla, P., and Kiang, C. S.: Gas-to-particle conversion of tropospheric sulfur as estimated from observations in the western North Pacific during PEM-West B, J. Geophys. Res., 102, 28 511-28 538, doi:10.1029/97JD01969, 1997.

Ball, S. M., Hanson, D. R., Eisele, F. L., and McMurry, P. H.: Laboratory studies of particle nucleation: Initial results for $\mathrm{H}_{2} \mathrm{SO}_{4}$, $\mathrm{H}_{2} \mathrm{O}$, and $\mathrm{NH}_{3}$ vapors, J. Geophys. Res., 104, 23 709-23 718, 1999.

Barth, M. C., Rasch, P. J., Kiehl, J. T., Benkovitz, C. M., and Schwartz, S. E.: Sulfur chemistry in the National Center for Atmospheric Research Community Climate Model: Description, evaluation, features, and sensitivity to aqueous chemistry, J. Geophys. Res., 105, 1387-1415, 2000.

Bates, T. S., Kapustin, V. N., Quinn, P. K., Covert, D. S., Coffman, D. J., Mari, C., Durkee, P. A., De Bruyn, W. J., and Saltzman, E. S.: Processes controlling the distribution of aerosol particles in the lower marine boundary layer during the First Aerosol Characterization Experiment (ACE 1), J. Geophys. Res., 103, 16369$16384,1998$.

Bohren, C. F.: Multiple scattering of light and some of its observable consequences, American Journal of Physics, 55, 524-533, 1987.

Brock, C. A., Hamill, P., Wilson, J. C., Jonsson, H. H., and Chan, K. R.: Particle formation in the upper tropical troposphere: a source of nuclei for the stratospheric aerosol, Science, 270, 1650-1653, 1995.

Carslaw, K. S., Clegg, S. L., and Brimblecombe, P.: A thermodynamic model of the system $\mathrm{HCl}-\mathrm{HNO}_{3}-\mathrm{H} 2 \mathrm{SO}_{4}-\mathrm{H}_{2} \mathrm{O}$, including solubilities of $\mathrm{HBr}$, from $<200 \mathrm{~K}$ to $328 \mathrm{~K}$, J. Phys. Chem., 99 , 11 557-11 574, 1995.

Clarke, A. D.: Atmospheric nuclei in the Pacific midtroposphere: Their nature, concentration, and evolution, J. Geophys. Res., 98, 20 633-20 648, doi:10.1029/93JD00797, 1993.

Clarke, A. D. and Kapustin, V. N.: A pacific aerosol survey. Part I: A decade of data on particle production, transport, evolution, and mixing in the troposphere, J. Atmos. Sci., 52, 363-382, 2002.

Clarke, A. D., Uehara, T., and Porter, J. N.: Lagrangian evolution of an aerosol column during the Atlantic Stratocumulus Transition Experiment, J. Geophys. Res., 101, 4351-4362, 1996. 
Clarke, A. D., Davis, D., Kapustin, V. N., Eisele, F., Chen, G., Paluch, I., Lenschow, D., Bandy, A. R., Thornton, D., Moore, K., Mauldin, L., Tanner, D., Litchy, M., Carroll, M. A., Collins, J., and Albercook, G.: Particle nucleation in the tropical boundary layer and its coupling to marine sulphur sources, Science, 282, 89-92, doi:10.1126/science.282.5386.89, 1998a.

Clarke, A. D., Varner, J. L., Eisele, F., Mauldin, R. L., Tanner, D., and Litchy, M.: Particle production in the remote marine tropospere: Cloud outflow and subsidence during ACE 1, J. Geophys. Res., 103, 16397-16409, 1998 b.

Clarke, A. D., Eisele, F., Kapustin, V. N., Moore, K., Tanner, D., Mauldin, L., Litchy, M., Lienert, B., Carroll, M. A., and Albercook, G.: Nucleation in the equatorial free troposphere: Favorable environments during PEM-Tropics, J. Geophys. Res., 104, 5735-5744, doi:10.1029/98JD02303, 1999.

Coffman, D. J. and Hegg, D. A.: A preliminary study of the effect of ammonia on particle nucleation in the marine boundary layer, J. Geophys. Res., 100, 7147-7160, doi:10.1029/94JD03253, 1995.

Covert, D. S., Kapustin, V. N., Bates, T. S., and Quinn, P. K.: Physical properties of marine boundary layer aerosol particles of the Mid Pacific in relation to sources and meteorological transport, J. Geophys. Res., 101, 6919-6930, 1996.

Curtius, J., Froyd, K. D., and Lovejoy, E. R.: Cluster ion thermal decomposition (I): Experimental kinetics study and ab initio calculations for $\mathrm{HSO}_{4}^{-}\left(\mathrm{H}_{2} \mathrm{SO}_{4}\right)_{(x)}\left(\mathrm{HNO}_{3}\right)_{(y)}$, J. Phys. Chem. A, 105, 10 867-10 873, 2001.

Dentener, F. J. and Crutzen, P. J.: A three-dimensional model of the global ammonia cycle, J. Atmos. Chem., 19, 331-369, 1994.

Deschamps, P. Y., Breon, F., Leroy, M., Podaire, A., Bricaud, A., Buriez, J. C., and Seze, G.: The POLDER Mission: Instrument Characteristics and Scientific Objectives, IEEE Trans. Geosc. Rem. Sens., 32, 598-615, 1994.

Dickinson, R. E.: Solar Variability and the Lower Atmosphere., Bull. Am. Meteorol. Soc., 56, 1240-1248, 1975.

Eichkorn, S., Wilhelm, S., Aufmhoff, H., Wohlfrom, K. H., and Arnold, F.: Cosmic ray-induced aerosol-formation: First observational evidence from aircraft-based ion mass spectrometer measurements in the upper troposphere, Geophys. Res. Lett., 29, doi:10.1029/2002GL015044, 2002.

Ekman, A. M. L., Wang, C., Ström, J., and Krejci, R.: Explicit simulation of aerosol physics in a cloud-resolving model: aerosol transport and processing in the free troposphere, J. Atmos. Sci., 63, 682-696, 2006.

Fischer, H., de Reus, M., Traub, M., Williams, J., Lelieveld, J., de Gouw, J., Warneke, C., Schlager, H., Minikin, A., Scheele, R., and Siegmund, P.: Deep convective injection of boundary layer air into the lowermost stratosphere at midlatitudes, Atmospheric Chemistry \& Physics, 3, 739-745, 2003.

Forbush, S. E.: Worldwide cosmic ray variations, 1937-1952, J. Geophys. Res., 59, 525-542, 1954.

Froyd, K. D. and Lovejoy, E. R.: Experimental Thermodynamics of Cluster Ions Composed of $\mathrm{H}_{2} \mathrm{SO}_{4}$ and $\mathrm{H}_{2} \mathrm{O}, 1$. Positive Ions, J. Phys. Chem. A, 107, 9800-9811, 2003a.

Froyd, K. D. and Lovejoy, E. R.: Experimental Thermodynamics of Cluster Ions Composed of $\mathrm{H}_{2} \mathrm{SO}_{4}$ and $\mathrm{H}_{2} \mathrm{O}, 2$. Measurements and ab Initio Structures of Negative Ions, J. Phys. Chem. A, 107, 9812-9824, 2003b.

Hõrrak, U., Salm, J., and Tammet, H.: Bursts of intermediate ions in atmospheric air, J. Geophys. Res., 103, 13 909-13 916, 1998.
Hegg, D. E., Radke, L. F., and Hobbs, P. V.: Particle production associated with marine clouds, J. Geophys. Res., 95, $13917-$ $13926,1990$.

Heintzenberg, J., Covert, D. S., and Van Dingenen, R.: Size distribution and chemical composition of marine aerosols: A compilation and review, Tellus, 52B, 1104-1122, 2000.

Higurashi, A. and Nakajima, T.: Development of a Two-Channel Aerosol Retrieval Algorithm on a Global Scale Using NOAA AVHRR, J. Atmos. Sci., 56, 924-941, 1999.

Higurashi, A., Nakajima, T., Holben, B. N., Smirnov, A., Frouin, R., and Chatenet, B.: A Study of Global Aerosol Optical Climatology with Two-Channel AVHRR Remote Sensing, J. Clim., 13, 2011-2027, 2000.

Katoshevski, D., Nenes, A., and Seinfeld, J. H.: A study of processes governing the maintenance of aerosols in the marine boundary layer, J. Aer. Sci., 30, 503-532, 1999.

Kawamoto, K., Nakajima, T., and Nakajima, T. Y.: A Global Determination of Cloud Microphysics with AVHRR Remote Sensing. J. Clim., 14, 2054-2068, 2001.

Kazil, J. and Lovejoy, E. R.: Tropospheric ionization and aerosol production: A model study, J. Geophys. Res., 109, D19206, doi: 10.1029/2004JD004852, 2004.

Kidwell, K. B.: NOAA Polar Orbiter Data User's Guide (TIROSN, NOAA-6, NOAA-7, NOAA-8, NOAA-9, NOAA-10, NOAA11, NOAA-12, NOAA-13 AND NOAA-14), Tech. rep., National Oceanic and Atmospheric Administration, U.S. Department of Commerce, National Oceanic and Atmospheric Administration, National Environmental Satellite, Data, and Information Service, National Climatic Data Center, Climate Services Division, Satellite Services Branch, FOB3, Room G233, E/CC33 5200 Auth Road, Suitland, MD 20746-4304, USA, 1998.

Korhonen, P., Kulmala, M., Laaksonen, A., Viisanen, Y., McGraw, R., and Seinfeld, J. H.: Ternary nucleation of $\mathrm{H}_{2} \mathrm{SO}_{4}, \mathrm{NH}_{3}$, and $\mathrm{H}_{2} \mathrm{O}$ in the atmosphere, J. Geophys. Res., 104, 26 349-26354, doi:10.1029/1999JD900784, 1999.

Kristjánsson, J. E. and Kristiansen, J.: Is there a cosmic ray signal in recent variations in global cloudiness and cloud radiative forcing?, J. Geophys. Res., 105, 11 851-11 864, 2000.

Kristjánsson, J. E., Staple, A., Kristiansen, J., and Kaas, E.: A new look at possible connections between solar activity, clouds and climate, Geophys. Res. Lett., 29, 22-1, doi:10.1029/ 2002GL0156460, 2002.

Kristjánsson, J. E., Kristiansen, J., and Kaas, E.: Solar activity, cosmic rays, clouds and climate - an update, Advances in Space Research, 34, 407-415, doi:10.1016/j.asr.2003.02.040, 2004.

Kulmala, M., Korhonen, P., Napari, I., Karlsson, A., Berresheim, H., and O'Dowd, C. D.: Aerosol formation during PARFORCE: Ternary nucleation of $\mathrm{H}_{2} \mathrm{SO}_{4}, \mathrm{NH}_{3}$, and $\mathrm{H}_{2} \mathrm{O}$, J. Geophys. Res., 107, 8111, doi:10.1029/2001JD000900, 2002.

Laakso, L., Anttila, T., Lehtinen, K. E. J., Aalto, P. P., Kulmala, M., Hõrrak, U., Paatero, J., Hanke, M., and Arnold, F.: Kinetic nucleation and ions in boreal forest particle formation events, Atmospheric Chemistry \& Physics, 4, 2353-2366, 2004.

Lean, J. and Rind, D.: Climate Forcing by Changing Solar Radiation, J. Clim., 11, 3069-3094, 1998.

Liu, X., Hegg, D. A., and Stoelinga, M. T.: Numerical simulation of new particle formation over the northwest Atlantic using the MM5 mesoscale model coupled with sulfur chemistry, J. Geophys. Res., 106, 9697-9716, doi:10.1029/2000JD900765, 2001. 
Lovejoy, E. R., Hanson, D. R., and Huey, L. G.: Kinetics and products of the gas-phase reaction of $\mathrm{SO}_{3}$ with water, J. Phys. Chem., 100, 19911-19916, doi:10.1021/jp962414d, 1996.

Lovejoy, E. R., Curtius, J., and Froyd, K. D.: Atmospheric ioninduced nucleation of sulfuric acid and water, J. Geophys. Res., 109, D08204, doi:10.1029/2003JD004460, 2004.

Lowder, W. M., Raft, P. D., and Beck, H. L.: Experimental Determination of Cosmic-Ray Charged Particle Intensity Profiles in the Atmosphere, in: Proceedings of the National Symposium on Natural and Manmade Radiation in Space, Las Vegas, Nevada, March 1-5, 1971, edited by: E. A., Warman, 908-913, NASA, Washington, nASA Report TM X-2440, 1972.

Marsh, N. and Svensmark, H.: Cosmic rays, clouds, and climate, Space Sci. Rev., 94, 215-230, 2000.

Marti, J. J., Jefferson, A., Ping Cai, X., Richert, C., McMurry, P. H., and Eisele, F.: $\mathrm{H}_{2} \mathrm{SO}_{4}$ vapor pressure of sulfuric acid and ammonium sulfate solutions, J. Geophys. Res., 102, 3725-3736, doi:10.1029/96JD03064, 1997.

Neher, H. V. and Forbush, S. E.: Correlation of cosmic ray-intensity and solar activity, Phys. Rev. Letters, 1, 173-174, 1958.

NOAA-CIRES Climate Diagnostics Center: NCEP/NCAR Reanalysis 1, http://www.cdc.noaa.gov, 2004.

O'Brien, K.: The theory of cosmic-ray and high-energy solarparticle transport in the atmosphere, in: The natural radiation environment VII, edited by: McLaughlin, J. P., Simopoulos, E. S., and Steinhäusler, F., Elsevier, seventh International Symposium on the Natural Radiation Environment, Rhodes, Greece, 20-24 May, 2002, 2005.

Pirjola, L., O’Dowd, C. D., Brooks, I. M., and Kulmala, M.: Can new particle formation occur in the clean marine boundary layer?, J. Geophys. Res., 105, 26 531-26 546, doi:10.1029/ 2000JD900310, 2000.

Raes, F.: Entrainment of free tropospheric aerosols as a regulating mechanism for cloud condensation nuclei in the remote marine boundary layer, J. Geophys. Res., 100, 2893-2903, 1995.

Raes, F. and Janssens, A.: Ion-induced aerosol formation in $\mathrm{a}_{2} \mathrm{O}$ $\mathrm{H}_{2} \mathrm{SO}_{4}$ system-I. Extension of the classical theory and search for experimental evidence, J. Aer. Sci., 16, 217-227, doi:10.1016/ 0021-8502(85)90028-X, 1985.

Raes, F. and Janssens, A.: Ion-induced aerosol formation in $\mathrm{a}_{2} \mathrm{O}-$ $\mathrm{H}_{2} \mathrm{SO}_{4}$ system-II, Numerical-calculations and conclusions, J. Aer. Sci., 17, 715-722, doi:10.1016/0021-8502(86)90051-0, 1993.

Raes, F. and Van Dingenen, R.: Simulations of condensation and cloud condensation nuclei from biogenic $\mathrm{SO}_{2}$ in the remote marine boundary layer, J. Geophys. Res., 97, 12 901-12 912, 1992.

Raes, F., Van Dingenen, R., Wilson, J., and Saltelli, A.: Cloud condensation nuclei from dimethyl sulphide in the natural marine boundary layer: Remote vs. in-situ production, in: Dimethylsulphide: Oceans, Atmosphere and Climate, European Coal and Steel Community, European Economic Community, European Atomic Energy Community, edited by: Restelli G. and Angeletti, G., Kluwer Academic, Proceedings of the International Symposium on DMS, Belgirate, Italy, 13-15 October 1992, pp. 311322, 1993

Raes, F., Van Dingenen, R., Cuevas, E., Van Velthoven, P. F. J., and Prospero, J. M.: Observations of aerosols in the free troposphere and marine boundary layer of the subtropical Northeast Atlantic: discussion of processes determining their size distribu- tion, J. Geophys. Res., 102, 21 315-21 328, 1997.

Rasch, P. J., Barth, M. C., Kiehl, J. T., Schwartz, S. E., and Benkovitz, C. M.: A description of the global sulfur cycle and its controlling processes in the National Center for Atmospheric Research Comminity Climate Model, Version 3, J. Geophys. Res., 105, 1367-1386, 2000.

Reid, G. C.: Influence of solar variability on global sea surface temperatures, Nature, 329, 142-143, doi:10.1038/329142a0, 1987.

Rossow, W. B. and Schiffer, R. A.: ISCCP Cloud Data Products, Bull. Am. Meteorol. Soc., 72, 2-20, 1991.

Rossow, W. B. and Schiffer, R. A.: Advances in Understanding Clouds from ISCCP, Bull. Am. Meteorol. Soc., 80, 2261-2287, 1999.

Satheesh, S. K., Ramanathan, V., Holben, B. N., Moorthy, K. K., Loeb, N. G., Maring, H., Prospero, J. M., and Savoie, D.: Chemical, microphysical, and radiative effects of Indian Ocean aerosols, J. Geophys. Res., 107, 4725, doi:10.1029/ 2002JD002463, 2002.

Schery, S. D. and Huang, S.: An estimate of the global distribution of radon emissions from the ocean, Geophys. Res. Lett., 31, L19 104, doi:10.1029/2004GL021051, 2004.

Seidel, D. J., Free, M., and Wang, J.: Diurnal cycle of upper-air temperature estimated from radiosondes, J. Geophys. Res., 110, D09 102, doi:10.1029/2004JD005526, 2005.

Sekiguchi, M., Nakajima, T., Suzuki, K., Kawamoto, K., Higurashi, A., Rosenfeld, D., Sano, I., and Mukai, S.: A study of the direct and indirect effects of aerosols using global satellite data sets of aerosol and cloud parameters, J. Geophys. Res., 108, 4-1, doi: 10.1029/2002JD003359, 2003.

Spivakovsky, C. M., Logan, J. A., Montzka, S. A., Balkanski, Y. J., Foreman-Fowler, M., Jones, D. B. A., Horowitz, L. W., Fusco, A. C., Brenninkmeijer, C. A. M., Prather, M. J., Wofsy, S. C., and McElroy, M. B.: Three-dimensional climatological distribution of tropospheric OH: Update and evaluation, J. Geophys. Res., 105, 8931-8980, doi:10.1029/1999JD901006, 2000.

Svensmark, H. and Friis-Christensen, E.: Variation of cosmic ray flux and global cloud coverage-a missing link in solar-climate relationships, J. Atmos. Terr. Phys., 59, 1225-1232, 1997.

Tsyganenko, N. A.: Tsyganenko 2003 model and related software (GEOPACK), NASA National Space Science Data Center, 2003.

Turco, R. P., Zhao, J.-X., and Yu, F.: A new source of tropospheric aerosols: Ion-ion recombination, Geophys. Res. Lett., 25, 635638, doi:10.1029/98GL00253, 1998.

Twohy, C. H., Clement, C. F., Gandrud, B. W., Weinheimer, A. J., Campos, T. L., Baumgardner, D., Brune, W. H., Faloona, I., Sachse, G. W., Vay, S. A., and Tan, D.: Deep convection as a source of new particles in the midlatitude upper troposphere, J. Geophys. Res., 107, 4560, doi:10.1029/2001JD000323, 2002.

Twohy, C. H., Petters, M. D., Snider, J. R., Stevens, B., Tahnk, W., Wetzel, M., Russell, L., and Burnet, F.: Evaluation of the aerosol indirect effect in marine stratocumulus clouds: Droplet number, size, liquid water path, and radiative impact, J. Geophys. Res., 110, D08 203, doi:10.1029/2004JD005116, 2005.

Twomey, S. A.: The influence of pollution on the shortwave albedo of clouds, J. Atmos. Sci., 34, 1148-1152, 1977.

Wang, Y., Liu, S. C., Anderson, B. E., Kondo, Y., Gregory, G. L., Sachse, G. W., Vay, S. A., Blake, D. R., Singh, H. B., and Thompson, A. M.: Evidence of convection as a major source of condensation nuclei in the northern midlatitude upper tropo- 
sphere, Geophys. Res. Lett., 27, 369-372, 2000.

Warren, S. G., Hahn, C. J., London, J., Chervine, R. M., and Jenne, R. L.: Global distribution of total cloud cover and cloud type amounts over land, Tech. Rep. NCAR/TN-273+STR, National Center for Atmospheric Research, 1986.

Weber, R. J., Marti, J. J., McMurry, P. H., Eisele, F. L., Tanner, D. J., and Jefferson, A.: Measurements of new particle formation and ultrafine particle growth rates at a clean continental site, J. Geophys. Res., 102, 4375-4385, 1997.

Weber, R. J., McMurry, P. H., Mauldin, R. L., Tanner, D. J., Eisele, F. L., Clarke, A. D., and Kapustin, V. N.: New particle formation in the remote troposphere: A comparison of observations at various sites, Geophys. Res. Lett., 26, 307-310, 1999.

Weber, R. J., Chen, G., Davis, D. D., Mauldin, R. L., Tanner, D. J., Eisele, F. L., Clarke, A. D., Thornton, D. C., and Bandy, A. R.: Measurements of enhanced $\mathrm{H}_{2} \mathrm{SO}_{4}$ and 3-4 nm particles near a frontal cloud during the First Aerosol Characterization Experiment (ACE 1), J. Geophys. Res., 106, 24 107-24 117, 2001a.

Weber, R. J., Moore, K., Kapustin, V., Clarke, A., Mauldin, R. L., Kosciuch, E., Cantrell, C., Eisele, F., Anderson, B., and Thornhill, L.: Nucleation in the equatorial Pacific during PEM-Tropics B: Enhanced boundary layer $\mathrm{H}_{2} \mathrm{SO}_{4}$ with no particle production, J. Geophys. Res., 106, 32 767-32 776, 2001 b.
White, W. B., Lean, J., Cayan, D. R., and Dettinger, M. D.: Response of global upper ocean temperature to changing solar irradiance, J. Geophys. Res., 102, 3255-3266, doi:10.1029/ 96JC03549, 1997.

White, W. B., Cayan, D. R., and Lean, J.: Global upper ocean heat storage response to radiative forcing from changing solar irradiance and increasing greenhouse gas/aerosol concentrations, J. Geophys. Res., 103, 21 355-21 366, doi:10.1029/98JC01477, 1998.

Yamato, M. and Tanaka, H.: Aircraft observations of aerosols in the free marine troposphere over the North Pacific Ocean: Particle chemistry in relation to air mass origin, J. Geophys. Res., 99, 5353-5378, doi:10.1029/93JD03191, 1994.

Yu, F.: Effect of ammonia on new particle formation: A kinetic $\mathrm{H}_{2} \mathrm{SO}_{4}-\mathrm{H}_{2} \mathrm{O}-\mathrm{NH}_{3}$ nucleation model constrained by laboratory measurements, J. Geophys. Res., 111, D01 204, doi: 10.1029/2005JD005968, 2005.

Yu, F. and Turco, R. P.: Ultrafine aerosol formation via ionmediated nucleation, Geophys. Res. Lett., 27, 883-886, 2000. 